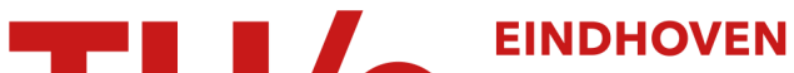 \\ UNIVERSITY OF \\ TECHNOLOGY
}

\section{Prediction of emulsion drop size distributions in colloid mills}

Citation for published version (APA):

Maindarkar, S. N., Dubbelboer, A., Meuldijk, J., Hoogland, H., \& Henson, M. A. (2014). Prediction of emulsion drop size distributions in colloid mills. Chemical Engineering Science, 118, 114-125.

https://doi.org/10.1016/j.ces.2014.07.032

DOI:

10.1016/j.ces.2014.07.032

Document status and date:

Published: 01/01/2014

\section{Document Version:}

Publisher's PDF, also known as Version of Record (includes final page, issue and volume numbers)

\section{Please check the document version of this publication:}

- A submitted manuscript is the version of the article upon submission and before peer-review. There can be important differences between the submitted version and the official published version of record. People interested in the research are advised to contact the author for the final version of the publication, or visit the $\mathrm{DOI}$ to the publisher's website.

- The final author version and the galley proof are versions of the publication after peer review.

- The final published version features the final layout of the paper including the volume, issue and page numbers.

Link to publication

\section{General rights}

Copyright and moral rights for the publications made accessible in the public portal are retained by the authors and/or other copyright owners and it is a condition of accessing publications that users recognise and abide by the legal requirements associated with these rights.

- Users may download and print one copy of any publication from the public portal for the purpose of private study or research.

- You may not further distribute the material or use it for any profit-making activity or commercial gain

- You may freely distribute the URL identifying the publication in the public portal.

If the publication is distributed under the terms of Article 25fa of the Dutch Copyright Act, indicated by the "Taverne" license above, please follow below link for the End User Agreement:

www.tue.nl/taverne

Take down policy

If you believe that this document breaches copyright please contact us at:

openaccess@tue.nl

providing details and we will investigate your claim. 


\title{
Prediction of emulsion drop size distributions in colloid mills
}

\author{
Shashank Maindarkar ${ }^{\mathrm{a}}$, Arend Dubbelboer ${ }^{\mathrm{b}}$, Jan Meuldijk ${ }^{\mathrm{b}}$, \\ Hans Hoogland ${ }^{\mathrm{c}}$, Michael Henson ${ }^{\mathrm{a}, *}$ \\ a Department of Chemical Engineering, University of Massachusetts, Amherst, MA 01003-9303, United States \\ ${ }^{\mathrm{b}}$ Department of Chemical Engineering and Chemistry, Technical University of Eindhoven, The Netherlands \\ ${ }^{c}$ Unilever $R \& D, 3133$ AT Vlaardingen, The Netherlands
}

\section{H I G H L I G H T S}

- Developed a population balance equation model for emulsification in colloid mill.

- Derived the function for drop breakage frequency in simple shear flow.

- Proposed a new daughter drop distribution function for capillary drop breakage.

- Used a viscosity model to predict the emulsion viscosity at high shear rates.

- Demonstrated good agreement between measured and predicted drop size distributions.

\section{A R T I C L E I N F O}

\section{Article history:}

Received 9 April 2014

Received in revised form

26 June 2014

Accepted 15 July 2014

Available online 24 July 2014

\section{Keywords:}

Colloid mill

Oil-in-water emulsions

Population balance equation model

Capillary breakage

Emulsion viscosity

\section{G R A P H I C A L A B S T R A C T}

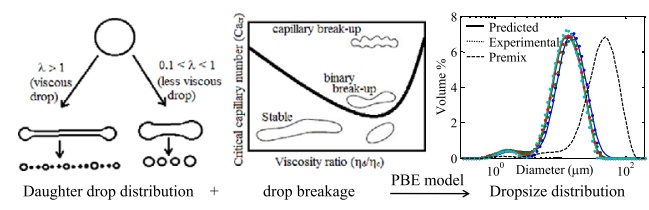

\begin{abstract}
A B S T R A C T
Colloid mills are the most common emulsification devices used in industry for products with high oil content. Drop breakage occurs when the emulsion is flowed through a small gap between rotor and stator under laminar shear conditions. In this paper, we have developed the first full population balance equation (PBE) model for colloid mills and used the model to better understand the relevant drop breakage mechanisms. The PBE model accounted for both drop breakage and coalescence and generated predictions of the drop size distribution after each pass of the emulsion through the colloid mill. Drops were assumed to break due to capillary instability with the distribution of drop sizes resulting from each breakage event studied in detail. A viscosity model was developed to predict the emulsion viscosity as function of the oil fraction and the high shear rates commonly used. Nonlinear optimization was used to estimate adjustable parameters in the breakage and coalescence functions to minimize the least-squares difference between predicted and measured drop size distributions for high oil-to-surfactant emulsions. We concluded that experimentally observed drop volume distributions could not be predicted with daughter drop distribution functions reported in the literature. Improved predictions were obtained using a new bimodal distribution function which captured drop breakage into multiple, nearly uniform daughter drops with a large number of small satellite drops. We also investigated model extensibility for changes in the oil fraction, emulsion flow rate and rotor speed.
\end{abstract}

Published by Elsevier Ltd.

\footnotetext{
* Corresponding author. Tel.: +1 413545 3481; fax: +1 4135451647 .

E-mail address: henson@ecs.umass.edu (M. Henson).
}

\section{Introduction}

Emulsions are heterogeneous system of two immiscible liquids in which one phase is dispersed in the other phase. Oil-in-water emulsions are commonly encountered in the food, pharmaceutical, 
agricultural, and consumer product industries. A minimal emulsion consists of water as the continuous phase, an oil as the dispersed phase and a surfactant that stabilizes formed oil droplets. The ingredients are mixed and drop sizes are reduced by applying mechanical energy to the emulsion. The size distribution of dispersed oil drops is a critical property of the emulsion that affects rheology, stability, texture, and appearance of the final product (McClements, 2005). The drop size distribution is known to depend on both the emulsion composition and the processing conditions (Walstra, 1993).

Emulsions are usually prepared via a two step process. In the first step, a coarse emulsion or premix is prepared by thoroughly mixing the ingredients in a low shear device. The coarse emulsion is then passed through a high energy mechanical device such as a high pressure homogenizer or a colloid mill. High pressure homogenization is generally preferred for low viscosity emulsions (Pandolfe, 1996) because sub-micron drops can be readily generated due to the high energy input. Colloid mills are the preferred technology for highly viscous emulsions ( > $5000 \mathrm{cp}$ ) commonly encountered in industry. A typical colloid mill consists of a conical rotor that rotates inside a static stator. As the emulsion is passed through the narrow gap between the rotor and stator, drop breakage occurs due to intense shearing. Additional passes of the emulsion through the colloid mill allow the drop size to be further reduced. While drop breakage in simple shear or Couette flow has been well studied (Cristini et al., 2003; Zhao, 2007; Renardy et al., 2002; Grace, 1982; Boonen et al., 2010), drop breakage mechanisms in colloid mills are not well understood. Common practice is to assume simple or extensional shear flow, in which drops break due to capillary instability when the ratio of the viscous stress to the interfacial tension force crosses a critical value (Wieringa et al., 1996; King and Keswani, 1994; Almeida-Rivera and Bongers, 2012).

A mathematical model that generates pass-by-pass predictions of the drop size distribution for different formulations and processing conditions would be a very valuable tool for colloid mill design and operation. Population balance equation (PBE) models have been successfully used to predict size distributions for other particulate processing devices including liquid-liquid dispersers (Alopaeus et al., 1999, 2002, 2003; Coulaloglou and Tavlarides, 1977; Kostoglou and Karabelas, 2001; Sovova, 1981; Sovova and Prochazka, 1981), liquid-liquid extractors (Ruiz et al., 2002; Ruiz and Padilla, 2004; Simon et al., 2003), and high pressure homogenizers (Hakansson et al., 2009a,b). We have developed a series of increasingly sophisticated PBE models for high pressure homogenizers that account for both breakage and coalescence (Raikar et al., 2009, 2010; Maindarkar et al., 2012, 2012). Perhaps due to the focus on homogenization, very few PBE models have been presented for colloid mills despite their industrial significance. Wieringa et al. (1996) developed a simple PBE model based on the assumption that the drop breakage frequency was the reciprocal of the breakage time, which in turn depended linearly on the drop size. An empirical equation for the number of daughter drops formed as a function of the capillary number was derived. Coalescence was completely neglected under the assumption that sufficient surfactant was available in solution for stabilization of newly formed drops. Also under the assumption of negligible coalescence, Almeida-Rivera and Bongers (2010) modeled the frequency of binary drop breakage to be proportional to $\left(d_{i}-d_{\max }\right)^{n}$, where $d_{i}$ is the drop diameter, $d_{\max }$ is the critical drop size below which drops cannot break, and $n$ is an adjustable model parameter. In addition to providing few insights into the relevant drop breakage mechanisms, these PBE models are not capable of accurate prediction due to their restrictive assumptions.

In this paper, the first PBE model of a colloid mill is developed that includes both drop breakage and coalescence. Drop breakage was assumed to follow the usual capillary instability mechanism with the number of daughter drops formed by a breakage event studied in detail. A new daughter drop distribution function consistent with previous experimental studies was formulated to improve PBE model predictions. The drop breakage and coalescence functions depend on the emulsion viscosity. The PBE model was integrated with a viscosity model that allowed the emulsion viscosity to be predicted as a function of the oil content and extrapolated to high shear rates. Adjustable model parameters were determined by nonlinear least-squares estimation using drop size distributions measured for multiple emulsification passes. The model was used to evaluate model extensibility with respect to the oil fraction, emulsion flow rate and rotor speed.

\section{Drop breakage and coalescence in colloid mills}

When an emulsion is passed through the narrow gap between the stator and the rotor rotating at high angular velocity (Fig. 1(a)), drop tends to stretch due to the very high shear rate $\dot{\gamma}\left(10^{4}-10^{6} 1 / \mathrm{s}\right)$. When the ratio of the viscous stress acting on the drop to the interfacial tension force surpasses some critical value, a mother drop breaks into two or more daughter drops. This ratio is called the capillary number Ca and is defined as Janssen et al. (1994)

$C a=\eta_{c} \dot{\gamma} d / 2 \sigma$

where $\eta_{c}$ is continuous phase viscosity; $d$ is the mother drop diameter; and $\sigma$ is the interfacial tension. The critical value is called the critical capillary number $C a_{c r}$ and depends on type of flow and the viscosity ratio of the dispersed and continuous phases $\left(\lambda=\eta_{d} / \eta_{c}\right)$. The situation is more complicated in high oil emulsions because droplets interact with each other. In this case, the continuous phase viscosity $\eta_{c}$ in the capillary number must be replaced by the apparent emulsion viscosity $\eta_{e m}$ and the viscosity ratio must be modified accordingly $\left(\lambda=\eta_{d} / \eta_{e m}\right)$.

Drop breakage in laminar shear flow is known to be very complex. When the capillary number is just slightly larger than the critical value such that $1 \leq \mathrm{Ca} / \mathrm{Ca}_{c r} \leq 2$, a drop breaks into two nearly equally sized daughter drops by an end-pinching mechanism (Region A in Fig. 1(b)) (Janssen et al., 1994; Wieringa et al., 1996; Zhao, 2007). When $\mathrm{Ca} / \mathrm{Ca}_{c r}>>1$ and $0.1<\lambda<1$, a drop breaks into many nearly equally sized daughter drops by a capillary mechanism (Region $\mathrm{C}$ in Fig. 1(b), (c)). When $\mathrm{Ca} / \mathrm{Ca}_{\mathrm{cr}}>>1$ and $\lambda>1$, a drop breaks into many unequally sized daughter or satellite drops (Region B in Fig. 1(b), (c)) (Zhao, 2007; Cristini et al., 2003). Adding to the complexity, $\mathrm{Ca}_{c r}$ is known to depend on the type of flow field in addition to the viscosity ratio. For example, drops with $\lambda>4$ will almost never break in simple shear flow because $C a_{c r}$ is too large, but such drop can break in extensional shear flow as $\mathrm{Ca}_{c r}$ is much smaller (Fig. 1(d)). Furthermore, Taylor vortices can appear in the flow field when the Taylor number $(\mathrm{Ta})$ exceeds some critical value $\left(T a_{c r}\right)$, which depends on the Reynolds number of flow. Taylor vortices have been experimentally observed for Reynolds number above 800 (Li et al., 2010). Simple calculations show that our emulsions prepared at 10 and $30 \mathrm{wt} \%$ oil will break due to Taylor vortices (Almeida-Rivera and Bongers, 2010) and not due to shearing in simple shear flow (Fig. 1(b)). The implications of this behavior for PBE modeling are discussed below.

Although colloid mills are designed to promote drop breakage, colliding drops may coalesce under certain conditions. The coalescence rate is determined by the frequency of collisions and the probability that a collision event will produce coalescence. The collision frequency depends on the local flow field, which is characterized by the local shear rate under laminar shear flow (Klink et al., 2011). By contrast, the coalescence probability depends on the ratio of the contact time between drops and the time required for drainage of the liquid film between the drops. The film 
a

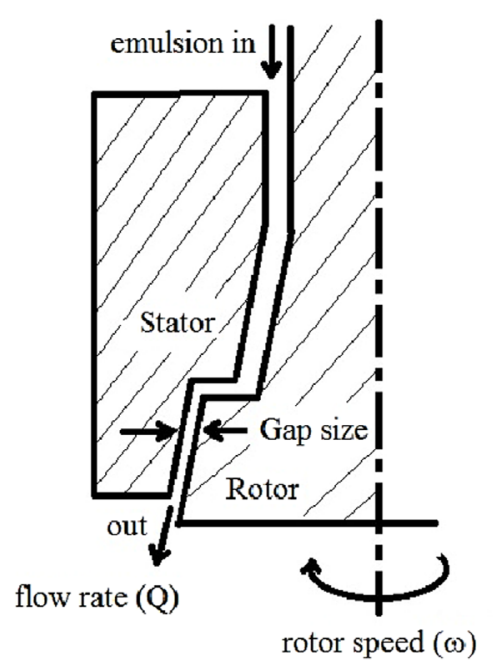

C

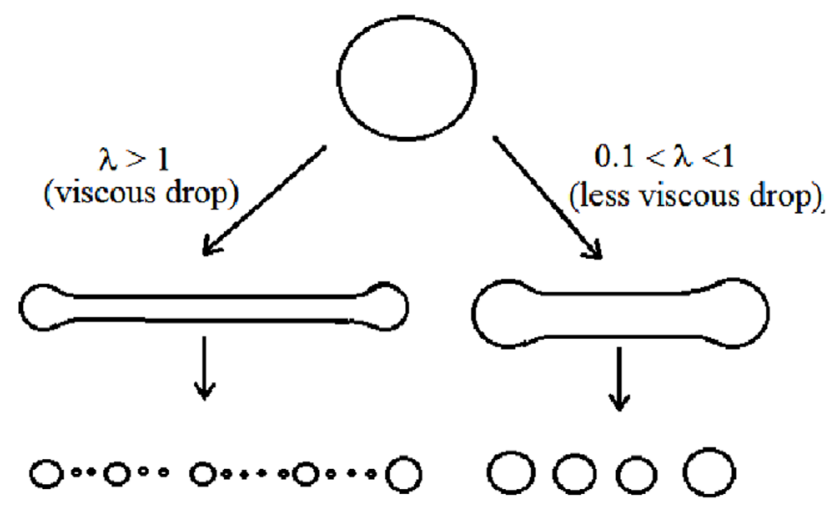

b

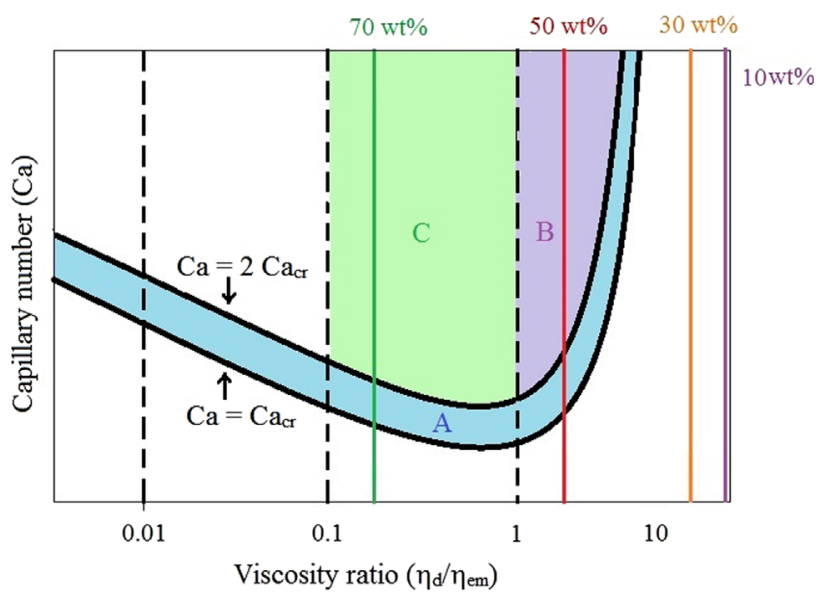

d

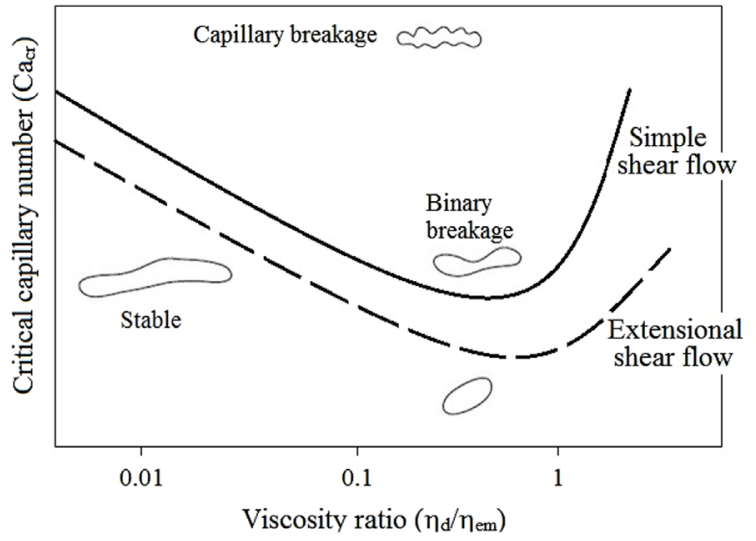

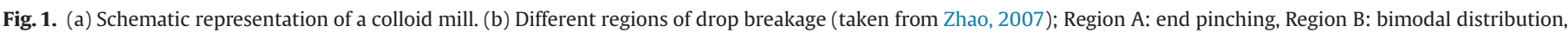

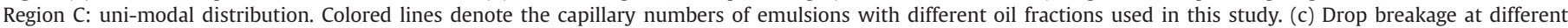

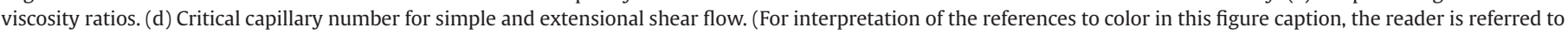
the web version of this article.)

thickness and drainage time depend on the drop capillary number and the viscosity ratio (Chesters, 1991). Experiments have shown that smaller drops (i.e. drops with smaller capillary numbers) have higher coalescence probabilities than larger drops, primarily because small drops have small film thicknesses (Chesters, 1991).

\section{Experimental methods}

\subsection{Materials}

Oil-in-water emulsions were prepared using commercial sunflower oil as the dispersed phase and ultrapure water as the continuous phase. A high oil-to-surfactant ratio (10:1) was used to mimic typical industrial conditions that promote drop coalescence. The base case emulsion (Table 1) consisted of $30 \mathrm{wt} \%$ oil, $3 \mathrm{wt} \%$ Pluronic F-68 surfactant (Sigma) and the remainder water. Other formulations with a 10:1 oil-to-surfactant ratio were used to cover a wide range of oil contents (10 wt\% oil, 1 wt\% Pluronic F-68; 50 wt\% oil, 5 wt\% Pluronic F-68; 70 wt\% oil, and 7 wt\% Pluronic F-68).

\subsection{Emulsion preparation}

Coarse emulsions were prepared by mixing the ingredients using a high shear mixer (LT5, Silverson). The coarse emulsion was
Table 1

Base case emulsion formulation and homogenization conditions.

\begin{tabular}{ll} 
Sunflower oil & $30 \mathrm{wt} \%$ \\
Pluronic F-68 surfactant & $3 \mathrm{wt} \%$ \\
Continuous phase density $\left(\phi_{c}\right)$ & $997 \mathrm{~g} / \mathrm{L}$ \\
Dispersed phase density $\left(\phi_{\mathrm{d}}\right)$ & $917 \mathrm{~g} / \mathrm{L}$ \\
Interfacial tension $(\sigma)$ & $27 \mathrm{mN} / \mathrm{m}$ \\
Premixing speed and time & $16,000 \mathrm{RPM}, 15 \mathrm{~min}$ \\
Colloid mill rotor speed $(\omega)$ & $5000 \mathrm{RPM}$ \\
Flow rate $(Q)$ & $16 \mathrm{~kg} / \mathrm{h}$ \\
Gap between rotor and stator & $2 \mathrm{~mm}$ \\
Number of passes & 4 \\
Emulsion viscosity at shear & $2.6 \mathrm{mPa} . \mathrm{s}$ \\
rate of $10^{5} 1 / \mathrm{s}\left(\eta_{e m}\right)$ & \\
\hline
\end{tabular}

passed through the colloid mill (Presto Mill PM30, Oskar-Krieger Ltd.) to achieve drop size reduction. Multiple emulsification passes were performed by repassing the emulsion through the colloid mill to further reduce the drop size. After each pass, approximately $2 \mathrm{ml}$ of the emulsion was sampled to analyze the drop size distribution. Emulsions were prepared at two different rotor speeds (5000, 10,000 RPM), three different flow rates $(16,35,70 \mathrm{~kg} / \mathrm{h})$ and two different gap sizes $(2,8 \mathrm{~mm})$ to test their impact on the drop size distribution. 


\subsection{Emulsion characterization}

Drop size distributions were measured using a static light scattering device (Mastersizer 2000, Malvern Instruments). Viscosities and the interfacial tension were measured prior to each homogenization experiment. Emulsion and dispersed phase viscosities were measured using a rheometer (2000EX, TA instruments) at $25^{\circ} \mathrm{C}$. The oilwater interfacial tension was measured by drop shape analysis (DSA-10 Tensiometer, KRUSS Instruments) at $25^{\circ} \mathrm{C}$.

\section{Theory}

\subsection{Population balance equation (PBE)}

The population balance equation (PBE) is particle number balance that accounts for rates of particle creation and disappearance (Ramkrishna, 2000). Although the gap region where breakage occurs is non-homogeneous (see Fig. 1(c)), we model the colloid mill as a well mixed system to avoid the complexities associated with modeling spatially dependent flow fields through computational fluid dynamics (Drumm et al., 2009; Zhang et al., 2009). The resulting PBE is (Coulaloglou and Tavlarides, 1977; Maindarkar et al., 2012)

$$
\begin{aligned}
\frac{\partial n(v, t)}{\partial t}= & -g(v) n(v, t)+\int_{v}^{\infty} \beta\left(v, v^{\prime}\right) g\left(v^{\prime}\right) n\left(v^{\prime}, t\right) d v^{\prime} \\
& -n(v, t) \int_{0}^{\infty} C\left(v, v^{\prime}\right) n\left(v^{\prime}, t\right) d v^{\prime}+\frac{1}{2} \int_{0}^{v} C\left(v-v^{\prime}, v^{\prime}\right) n\left(v-v^{\prime}, t\right) n\left(v^{\prime}, t\right) d v^{\prime}
\end{aligned}
$$

where $v$ is the volume of the droplet; $n(v, t) d v$ is the number of drops with volume in the range $[v, v+d v]$ at time $t ; \beta\left(v, v^{\prime}\right)$ is the daughter drop distribution function which represents the probability of forming a daughter drop of size $v$ from breakage of a mother drop of size $v^{\prime}$; $g(v)$ is the breakage frequency which represents the fraction of drops of volume $v$ breaking per unit time; and $C\left(v, v^{\prime}\right)$ is the coalescence frequency which represents the rate at which drops of size $v$ and size $v^{\prime}$ coalesce. The first and third terms on the right hand side of Eq. (2) account for disappearance of drops of size $v$ due to breakage and coalescence, respectively, while the second and fourth terms account for the appearance of drops of size $v$. The functions that describe the breakage and coalescence processes, namely $g(v), \beta\left(v, v^{\prime}\right)$ and $C\left(v, v^{\prime}\right)$, are described below.
The PBE (2) describes the evolution of the number of drops of different sizes $n(v, t) d v$, while standard particle size analyzers provide measurements of the volume percent distribution. Under the reasonable assumption that drops are spherical, the volume percent distribution of drops can be represented as follows:

$n(v, t)=\frac{V_{t o t} n_{p}(v, t)}{v}$

where $n_{p}(v, t) d v$ is the volume fraction of drops in the range $[v, v+d v]$ at time $t$ and $V_{\text {tot }}$ is the conserved total volume of the drops. The PBE (2) can be reformulated in terms of $n_{p}(v, t)$ to yield

$$
\begin{aligned}
\frac{\partial n_{p}(v, t)}{\partial t}= & -g(v) n_{p}(v, t)+v \int_{v}^{\infty} \frac{\beta\left(v, v^{\prime}\right) g\left(v^{\prime}\right) n_{p}\left(v^{\prime}, t\right)}{v^{\prime}} d v^{\prime} \\
& -n_{p}(v, t) \int_{0}^{\infty} \frac{C\left(v, v^{\prime}\right) n_{p}\left(v^{\prime}, t\right) V_{t o t}}{v^{\prime}} d v^{\prime} \\
& +\frac{v}{2} \int_{0}^{v} \frac{C\left(v-v^{\prime}, v^{\prime}\right) n_{p}\left(v-v^{\prime}, t\right) n_{p}\left(v^{\prime}, t\right) V_{t o t}}{v^{\prime}\left(v-v^{\prime}\right)} d v^{\prime}
\end{aligned}
$$

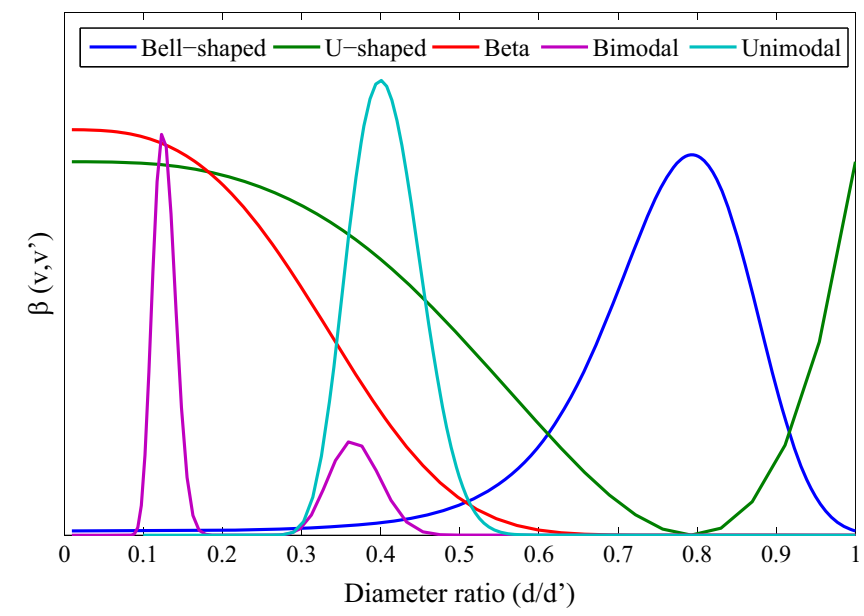

Fig. 2. Daughter drop distribution functions: (1) bell-shaped function; (2) U-shaped function; (3) beta function $(p=15)$; (4) new bimodal function $\left(M_{1}=1, M_{2}=\right.$ $\left.27 ; M_{3}=512\right)$; and (5) new unimodal function $\left(M_{4}=2162, M_{5}=17.5\right)$.

Table 2

\begin{tabular}{|c|c|c|}
\hline$\beta\left(v, v^{\prime}\right)$ & Reference & \\
\hline$\beta\left(v, v^{\prime}\right)=\frac{p}{v^{\prime}}(p-1)\left(1-\frac{v}{v^{\prime}}\right)^{p-2}$ & $\begin{array}{l}\text { Hill and } \mathrm{Ng} \\
(1996)\end{array}$ & $\begin{array}{l}\text { Beta function: } p \text { daughter drops form with equal probability of daughter drops of any size }\left(v<v^{\prime}\right) \text { being formed } \\
\text { due to breakage of a mother drop of size } v^{\prime}\end{array}$ \\
\hline$\beta\left(v, v^{\prime}\right)=4.8 \exp \left[-4.5\left(4 \frac{v}{v^{\prime}} 2-\frac{v}{v^{\prime}}+1\right)\right]$ & $\begin{array}{l}\text { Liao and Lucas } \\
(2009)\end{array}$ & Bell-shaped distribution function: mother drop breaks into two nearly equal sized daughter drops \\
\hline$\beta\left(v, v^{\prime}\right)=37.75\left(\frac{1}{\frac{v}{v^{\prime}}+1}+\frac{1}{2-\frac{v}{v^{\prime}}}-1.33\right)$ & $\begin{array}{l}\text { Liao and Lucas } \\
(2009)\end{array}$ & U-shaped distribution function: mother drop breaks into two unequal sized daughter drops \\
\hline
\end{tabular}

Reynolds numbers for emulsions prepared with different oil weight fractions.

\begin{tabular}{lllc}
\hline Emulsion oil fraction (wt\%) & Emulsion density $\left(\mathrm{kg} / \mathrm{m}^{3}\right)$ & Emulsion viscosity $(\mathrm{Pa} \cdot \mathrm{s})$ & Reynolds number $\left(R e=\rho_{e m} \omega R_{i} h / \eta_{e m}\right)$ \\
\hline 10 & 989 & 0.0013 & 2536 \\
30 & 972 & 0.0032 & 1013 \\
50 & 955 & 0.0147 & 216 \\
70 & 940 & 0.5652 & 5.5 \\
\hline
\end{tabular}

Table 3

Daughter drop distribution functions. 


\subsection{PBE functions}

The PBE (2) contains three functions $\left(g(v), \beta\left(v, v^{\prime}\right), C\left(v, v^{\prime}\right)\right)$ that must be specified to compute the drop size distribution. The

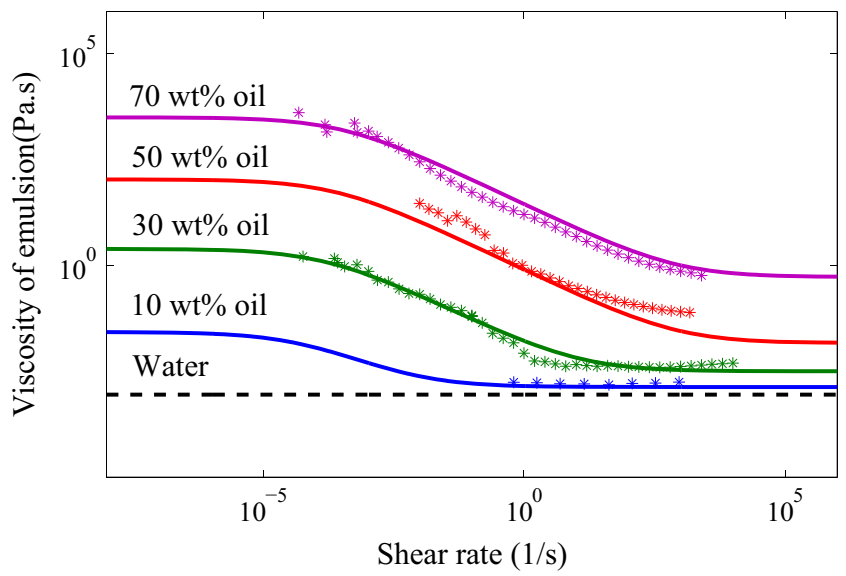

Fig. 3. Emulsion viscosity predictions at different oil volume fractions and shear rates with model parameters $K_{2}=19.5, k=1900, m=0.59, a_{1}=0.8, a_{2}=0.2$ and $a_{3}=0.01$.

a

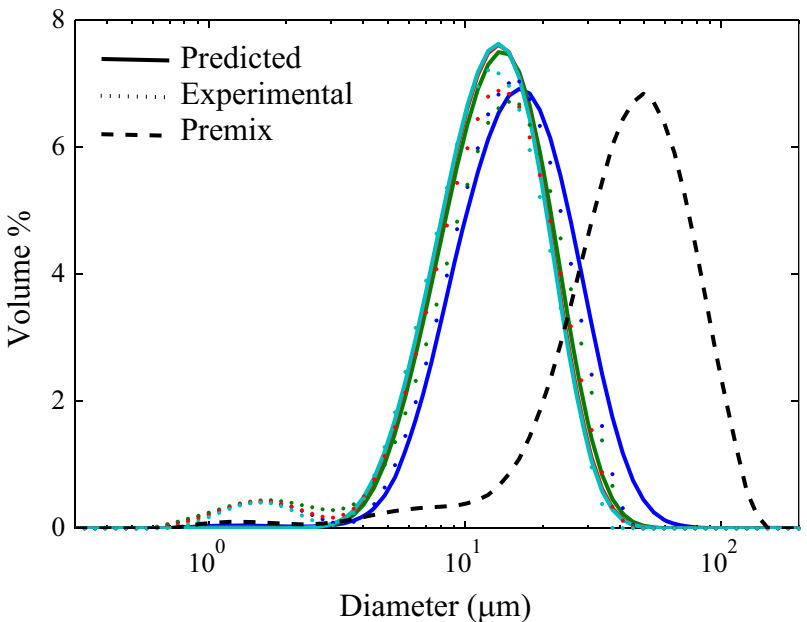

C

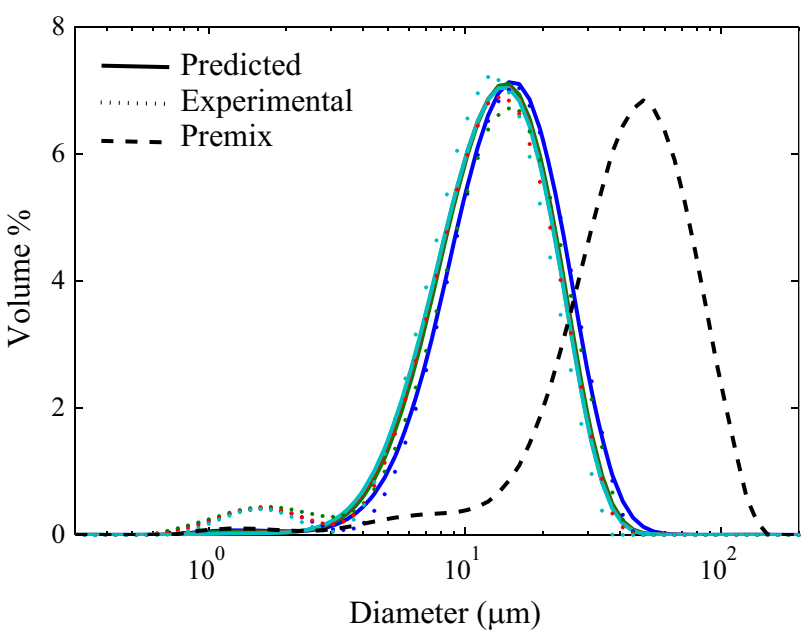

coalescence frequency $C\left(v, v^{\prime}\right)$ of drops of size $v$ and $v^{\prime}$ can be modeled as the product of the drop collision frequency $F\left(v, v^{\prime}\right)$ and the coalescence efficiency $E\left(v, v^{\prime}\right)$ (Coulaloglou and Tavlarides, 1977). For the case of simple shear flows, the coalescence frequency can be calculated as function of the shear rate $\dot{\gamma}$ and the oil volume fraction $\phi$ as follows (Klink et al., 2011):

$F\left(v, v^{\prime}\right)=K_{1} \frac{\dot{\gamma}}{(1-\phi)}\left(v^{1 / 3}+v^{\prime 1 / 3}\right)^{3}$

where $K_{1}$ is an adjustable model parameter. The average shear rate in Couette flow is calculated from rotor speed $(\omega)$ by

$\dot{\gamma}=\frac{2 \pi \omega R_{1}}{R_{2}-R_{1}}$

where $R_{1}$ is the radius of the rotor and $R_{2}$ is inner radius of the stator. The coalescence efficiency depends on the contact time between two drops and the time required for drainage of the liquid film between the two drops. If the contact time exceeds the film drainage time, the drops will coalesce. We used the following expression originally derived for the coalescence efficiency of partially mobile, deformable drops (Chesters, 1991):

$E\left(v, v^{\prime}\right)=\exp \left[-K_{2} \frac{\eta_{d}}{\eta_{e m}} \operatorname{Ca}\left(v_{e q}\right)^{3 / 2}\left(\frac{\sigma v_{e q}^{2}}{A}\right)^{1 / 3}\right] ; \quad v_{e q}=\frac{12}{\pi} \frac{v^{1 / 3} v^{1 / 3}}{v^{1 / 3}+v^{\prime 1 / 3}}$

b

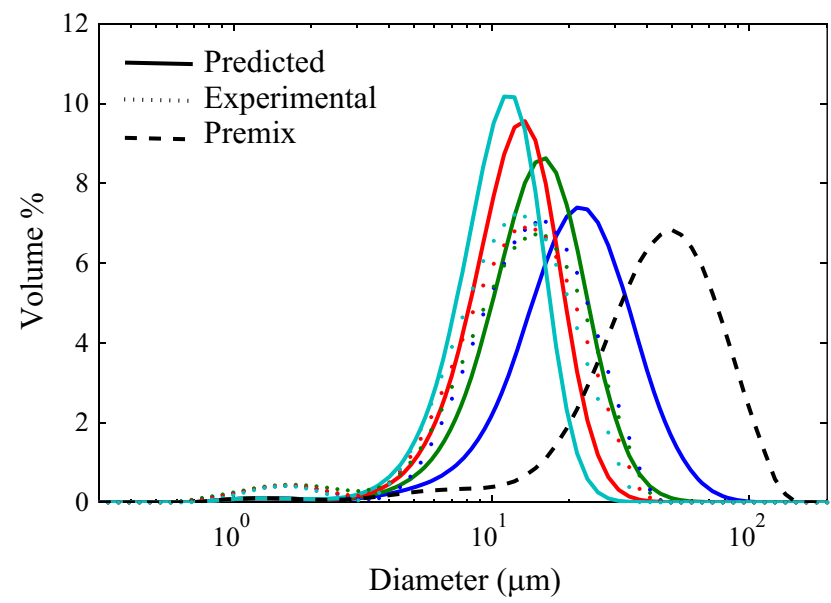

d

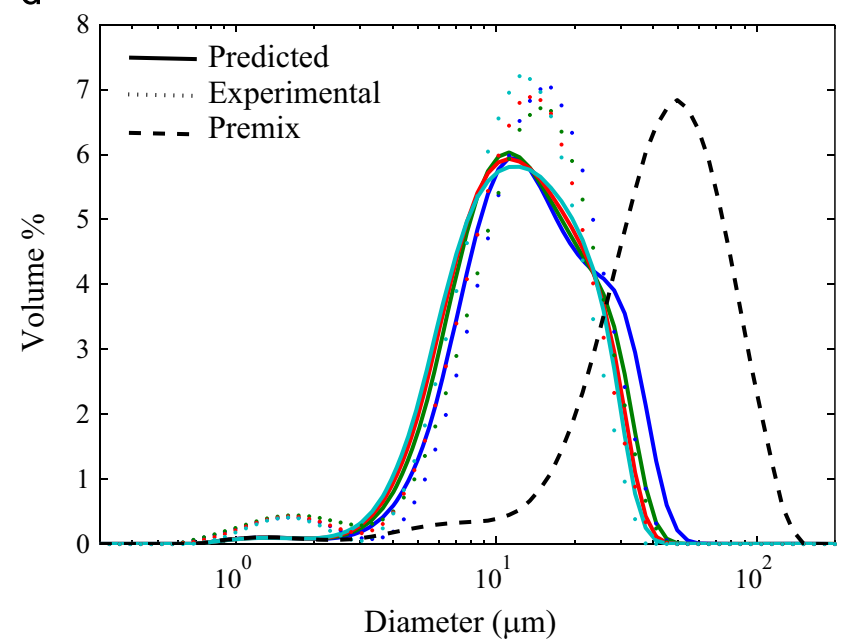

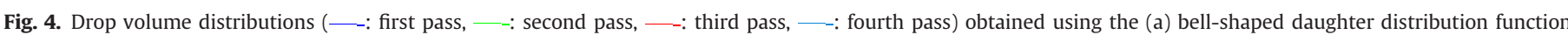

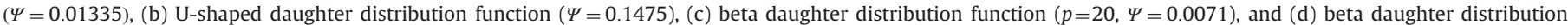
function ( $p=200, \Psi=0.0401)$ for the base case conditions. 
where $v_{e q}$ is the equivalent diameter of colliding drops of volume $v$ and $v^{\prime}, A$ is Hamaker constant and $K_{2}$ is an adjustable model parameter.

We assumed that the drop breakage frequency $g(v)$ is determined by the capillary number $\mathrm{Ca}$ of the drop. If $\mathrm{Ca}$ is more than the critical capillary number $\mathrm{Ca}_{c r}$, the drop will stretch under shear flow and break into smaller daughter drops. The following expression was derived under the assumption that the breakage frequency is proportional to the shear rate $\dot{\gamma}$ :

$g(v)=K_{3} \dot{\gamma} \exp \left(-K_{4} \frac{C a_{c r}}{C a(v)}\right)=K_{3} \dot{\gamma} \exp \left(-K_{4} \frac{C a_{c r} \sigma}{\dot{\gamma} \eta_{e m} v^{1 / 3}}\right)$

where $K_{3}$ and $K_{4}$ are adjustable model parameters. The critical capillary number was calculated by solving the following empirical equation developed for simple shear flow (De Bruijn, 1989):

$$
\begin{gathered}
0.94 \log (\lambda)^{2}+1.11 \log (\lambda) \log \left(10 C a_{c r}\right)-2.15 \times 10^{-5} \log \left(10 C a_{c r}\right)^{2} \\
-0.0038 \log (\lambda)-1.5 \log \left(10 C a_{c r}\right)+1=0
\end{gathered}
$$

Due to high Reynolds numbers (Table 2), drop breakage in our emulsions prepared at 10 and $30 \mathrm{wt} \%$ oil is expected to be caused by Taylor vortices (Almeida-Rivera and Bongers, 2010) and not by simple shear flow (Fig. 1(b)). Unlike drop breakage in simple Couette flow, the breakage of drops in Taylor vortices is not well studied. Drops smaller than the Taylor vortices break due to viscous shear when the shear stress $\left(\eta_{\text {em }} \gamma_{\text {TV }}\right)$ becomes more than the Laplace pressure $(4 \sigma / d)$. Thus the breakage frequency would be expected to depend on the ratio of local viscous shear stress to the surface tension force. Because no method is available to calculate the local shear rate in Taylor vortices, we assumed the average local shear rate to be proportional to the rotor speed for simplicity. The breakage frequency function (8) was derived assuming the frequency depends on the ratio of the viscous stress to the surface tension force as represented by the capillary number. Therefore we used the breakage frequency function (8) with $C a_{c r}=1$ and a distinct set of adjustable constants $\left(K_{3}, K_{4}\right)$ to describe drop breakage due to Taylor vortices.

Based on our previous work on PBE modeling of high pressure homogenizers (Maindarkar et al., 2012, 2012), we considered the beta function as the daughter drop distribution function $\beta\left(v, v^{\prime}\right)$ (see Table 3). The beta function describes the breakage of a mother drop of size $v^{\prime}$ into $p$ daughter drops with the equal probability of daughter drops of any size $\left(v<v^{\prime}\right)$ being formed. In this paper, the number of daughter drops $p=15$. We have found that PBE model predictions are not highly sensitive to this parameter as long as $p$ is sufficiently larger. We also investigated the other commonly used drop distribution functions listed in Table 3.

We also formulated a new daughter drop distribution function that better captured drop breakage under laminar shear flow conditions commonly encountered in colloid mills. When the viscous shear force

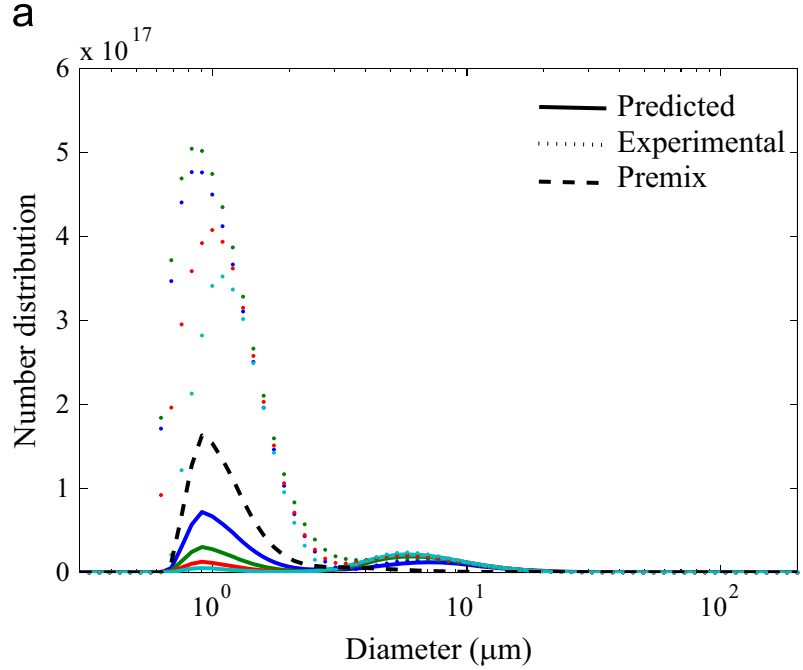

b
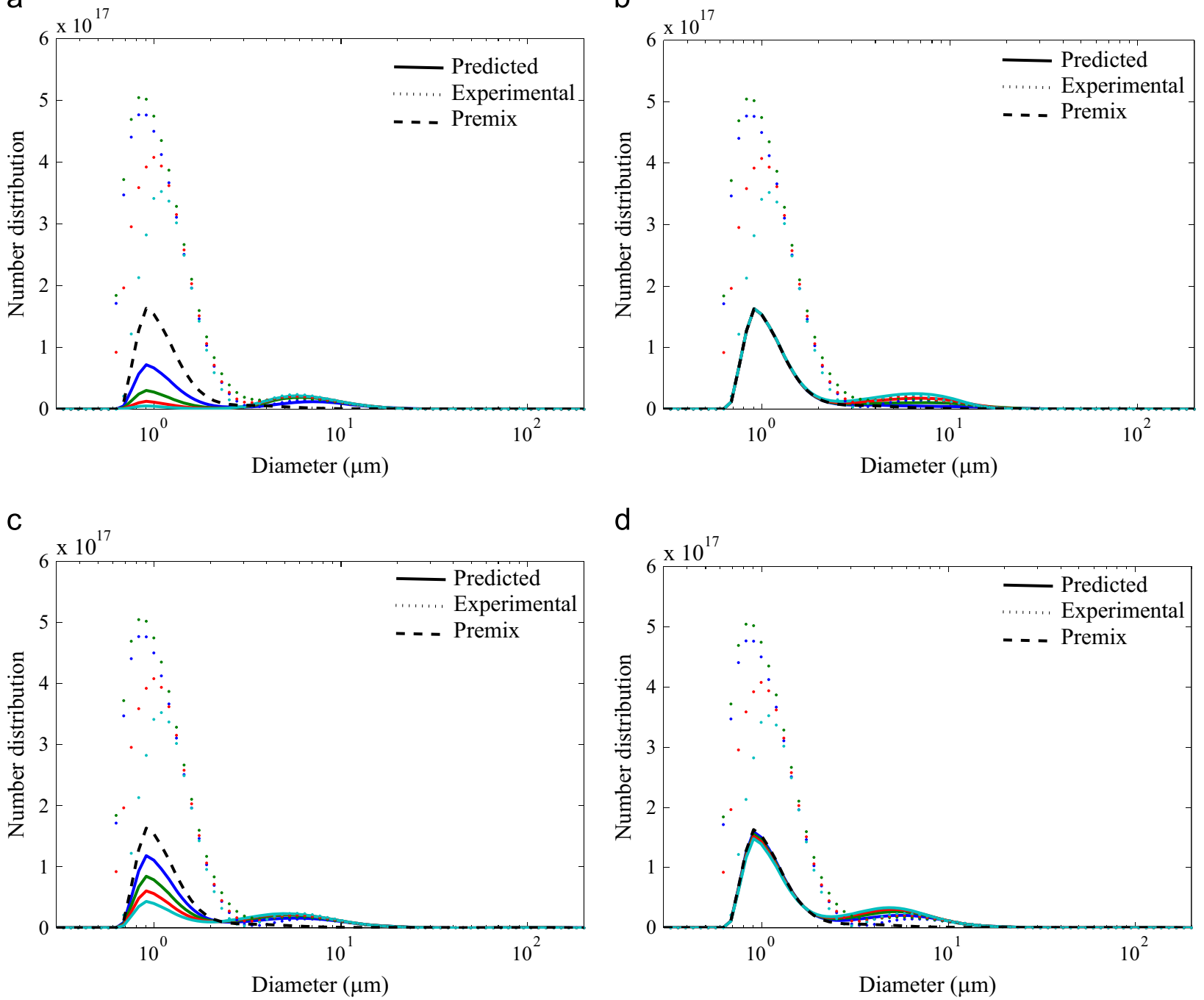

d

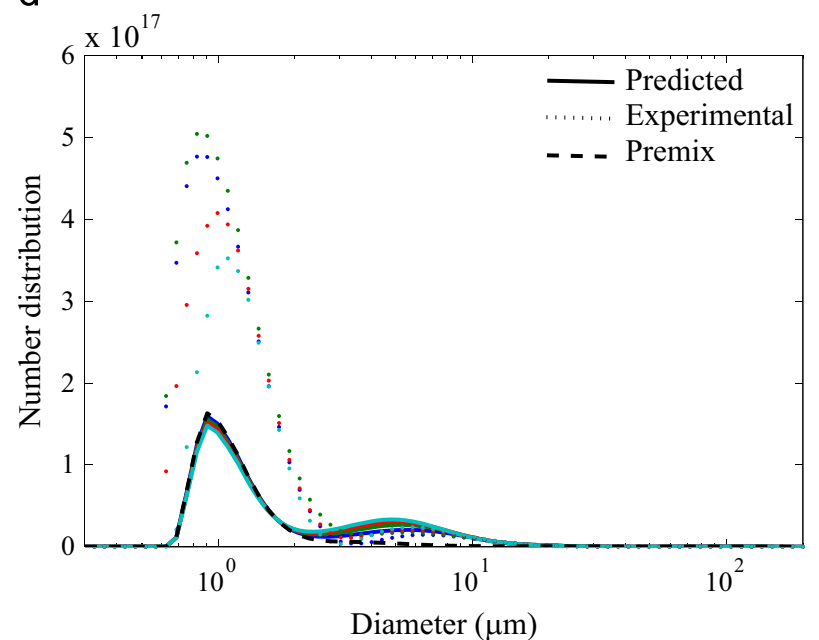

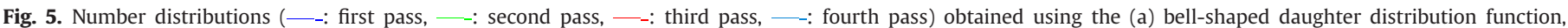
(b) U-shaped daughter distribution function, (c) beta daughter distribution function $(p=20)$, and (d) beta daughter distribution function ( $p=200$ ) for the base case conditions. 
overcomes the surface tension force, drops elongate and break to form large number of very small satellite drops (Zhao, 2007). Hence, the following bimodal daughter distribution function (Fig. 2) was formulated:

$\beta_{N}\left(v, v^{\prime}\right)=M_{1} \exp \left[\frac{-1}{\left(\frac{8 v}{v^{\prime}}\right)^{2}+\left(\frac{v^{\prime}}{M_{2} v}\right)^{2}}\right] \exp \left[-\left(\frac{M_{3} v}{v^{\prime}}\right)^{2}\right] \exp \left[-\left(\frac{v^{\prime}}{M_{3} v}\right)^{2}\right]$

where $M_{2}$ is a parameter that determines the size of satellite drops and $M_{3}$ is a parameter that determines the relative probability of forming smaller drops and satellite drops. The parameter $M_{1}$ is chosen to ensure that the following volume conservation equation is satisfied:

$\int_{0}^{v \prime} \beta_{N}\left(v, v^{\prime}\right) v d v=v^{\prime}$

The choice of the parameters $M_{2}$ and $M_{3}$ is discussed below.

The bimodal distribution function is valid for emulsions with viscosity ratios greater than one. For emulsions with viscosity ratios less than one, a mother drop breaks into nearly uniform daughter drops due to stretching in the shear flow (Zhao, 2007). For this situation, a new uni-modal function was developed

$\beta\left(v, v^{\prime}\right)=M_{4} \exp \left[-\left(\frac{v^{\prime}}{M_{5} v}\right)^{2}\right] \exp \left[-\left(\frac{M_{5} v}{v^{\prime}}\right)^{2}\right]$

a

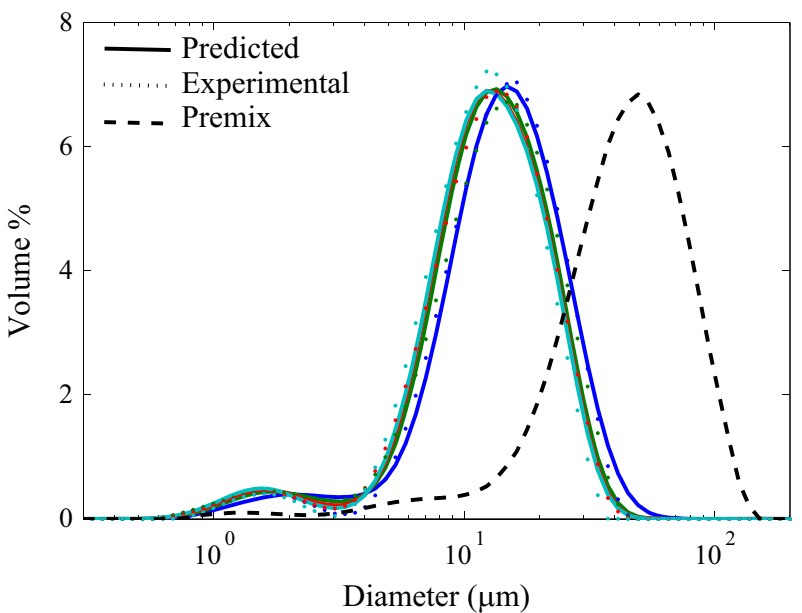

where $M_{5}$ is a parameter that determines the size of daughter drops and $M_{4}$ is a parameter that ensures volume conservation by satisfying equation (11). The choice of the parameter $M_{5}$ is discussed below. All the daughter drop distribution functions used in this study are plotted in Fig. 2 for comparison. The parameters $M_{2}$ and $M_{3}$ in the new bimodal function (Eq. (10)) were chosen to yield a small peak at larger drop sizes to capture the formation of a small number of large drops and a large peak at small drop sizes to capture the formation of very large number of small satellite drops. We found that model predictions were relatively insensitive to the value of $M_{5}$ in the new unimodal function (Eq. (12)) which was chosen to yield 15 equally sized daughter drops from breakage of a mother drop by satisfying following equation for average number of daughter drops $(p)$ (Kumar and Ramkrishna, 1996):

$p=\int_{0}^{v \prime} \beta\left(v, v^{\prime}\right) d v$

\subsection{Emulsion viscosity model}

Typically the continuous (water) phase viscosity is used to calculate the capillary number (Janssen et al., 1994). To capture the apparent viscosity of the fluid surrounding the drops, the continuous phase viscosity should be replaced with the emulsion viscosity for non-dilute oil mixtures. To generate a predictive model, the emulsion viscosity $\eta_{e m}$ must be calculated from known variables including the shear rate

b

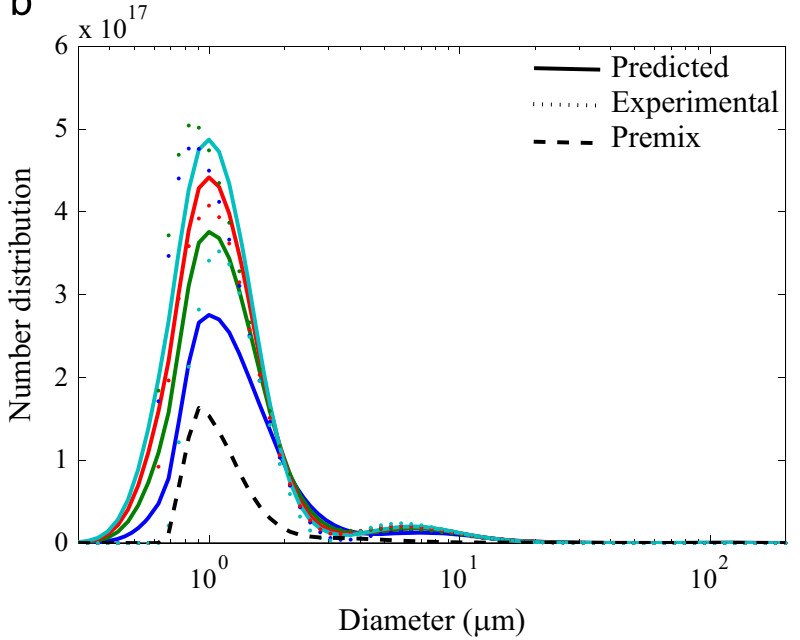

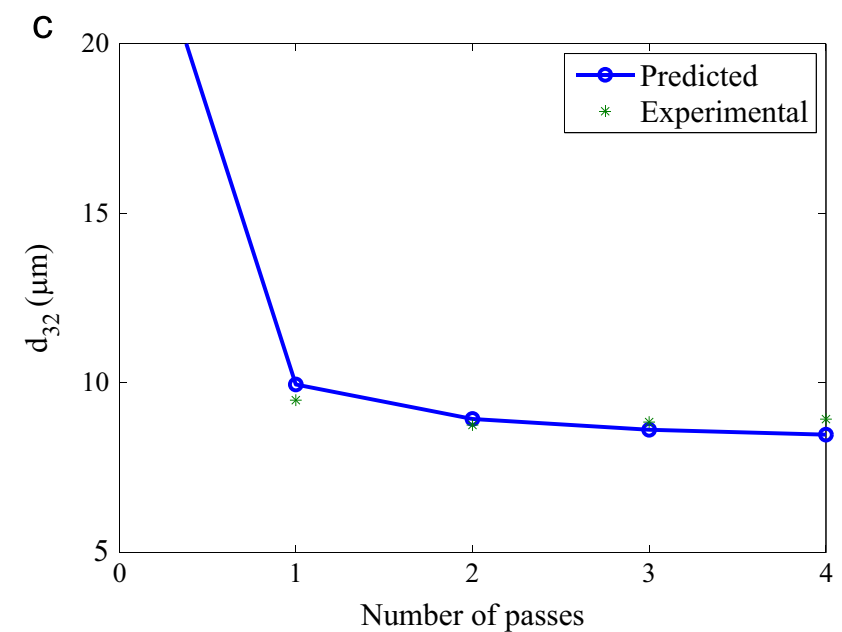

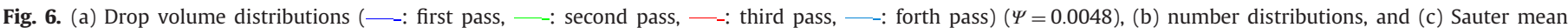
diameter obtained using the proposed bimodal daughter drop distribution function for base case conditions. 
$\dot{\gamma}$, the oil volume fraction $\phi$, density $\rho_{d}$ and viscosity $\eta_{d}$, the continuous phase density $\rho_{c}$ and viscosity $\eta_{c}$, the surfactant concentration and the temperature $T$. Several models have been developed predicting the emulsion viscosity from these variables (Derkach, 2009; Pal, 2001; Jansen et al., 2001; Barnes, 1994). At very low shear rates, the oil drops exist in a three-dimensional isotropic and random distribution resulting in a constant viscosity. As the shear rate increases, the drops start to align along the stream lines and the viscosity decreases due to reduced resistance to the fluid flow. At very high shear rate, drops cannot align any further and the emulsion behaves as a Newtonian fluid with a constant viscosity. Assuming no temperature change during emulsification, the emulsion viscosity was predicted as a function of the shear rate using the following model (Jansen et al., 2001):

$$
\begin{aligned}
\frac{\eta_{e m}}{\eta_{c}} & =\eta_{\infty}+\frac{\eta_{0}-\eta_{\infty}}{1+K F^{m}} ; \quad F=\frac{4 \pi \eta_{c} \dot{\gamma} d_{32}^{2} d_{m}}{k T \phi} \\
\eta_{0} & =\exp \left(K_{\lambda} \phi^{a 1}\right), \quad \phi<=\phi_{c} \\
& =\exp \left(K_{\lambda} \phi^{a 1}\right)\left(1+a_{2}\left(\phi-\phi_{c}\right)\right), \quad \phi>\phi_{c} \\
\eta_{\infty} & =\exp \left(\frac{\frac{2.5 \lambda+1}{\lambda+1} \phi}{1-\phi}\right), \quad \phi<=\phi_{c} \\
& =\exp \left(\frac{\frac{2.5 \lambda+1}{\lambda+1} \phi}{1-\phi}\right) \exp \left(a_{3}(\lambda+1)\left(\phi-\phi_{c}\right)\right), \quad \phi>\phi_{c}
\end{aligned}
$$

where $d_{32}$ is the Sauter mean diameter of the emulsion drops; $d_{m}$ is hydrodynamic diameter of the surfactant molecule (assumed to be 30 $A^{o}$ based on typical values of $\left.d_{m}\right) ; \phi_{c}$ is the critical oil volume fraction above which drops are in close contact and the interaction mechanism changes (assumed to be 0.6 from Jansen et al., 2001); $k$ is the Boltzmann constant $\left(1.38 \times 10^{-23} \mathrm{~J} / \mathrm{K}\right) ; K_{\lambda}, K, m$, and $a_{1}$ are fitting parameters for $\phi \leq \phi_{c}$; and $a_{2}$ and $a_{3}$ are additional fitting parameters for $\phi>\phi_{c}$. As the shear rate $\dot{\gamma}$ in increased, the ratio $\eta_{e m} / \eta_{c}$ asymptotically approaches the value $\eta_{\infty}$. Therefore, the model (14) can be extrapolated to very high shear rates $\left(>10^{4} 1 / \mathrm{s}\right.$ ) to calculate the emulsion viscosity inside a colloid mill. The viscosity model parameters were estimated by minimizing the least square error between measured and predicted viscosity values over a range of shear rates and oil fractions. The minimization problem was solved with the Matlab function 1sqnonlin.

\subsection{Dynamic simulation and parameter estimation}

The PBE (2) was solved numerically by approximating the integral expression using the fixed pivot technique (Kumar and Ramkrishna, 1996) with 100 equally spaced node points. While there were small changes in solutions after increasing the number of node points, these small improvements were accompanied by substantial increases in the computational cost for simulation and

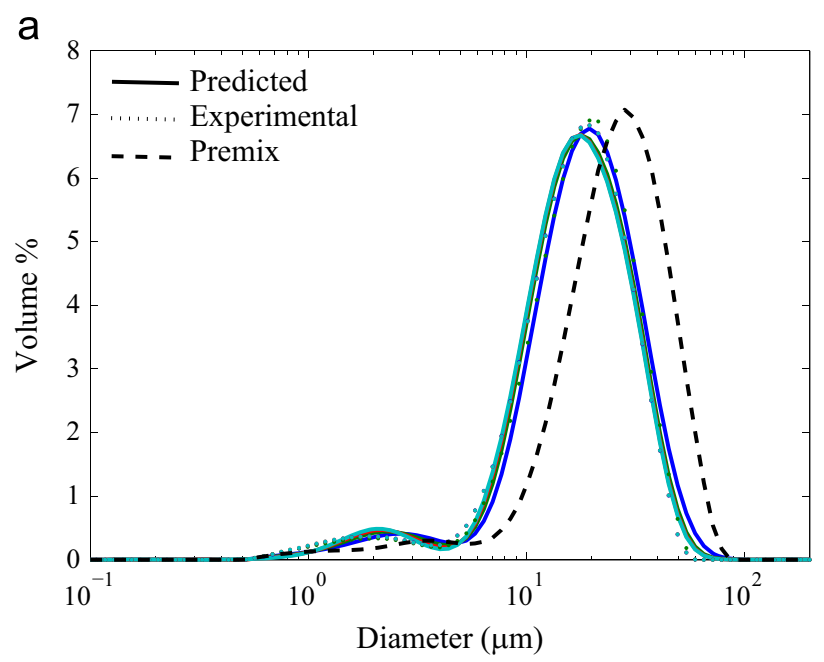

b

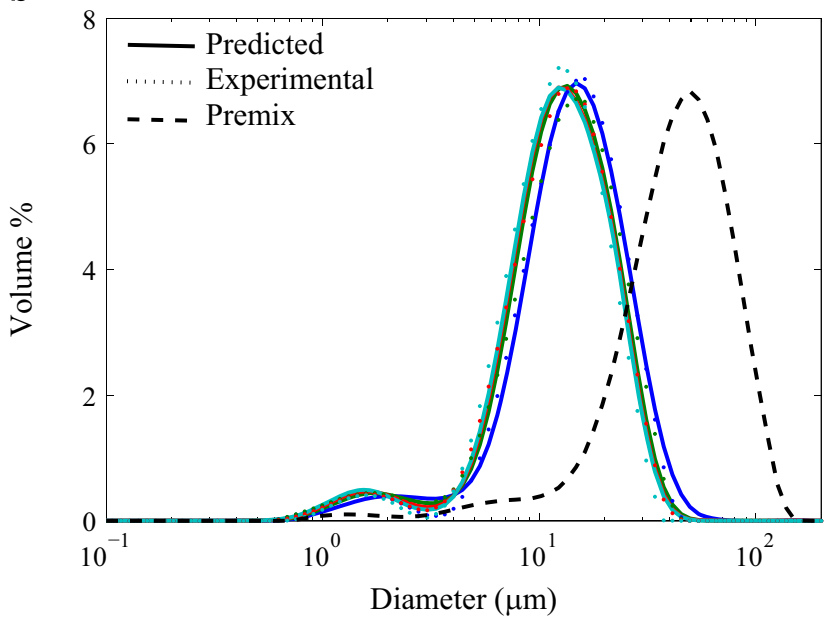

C

d
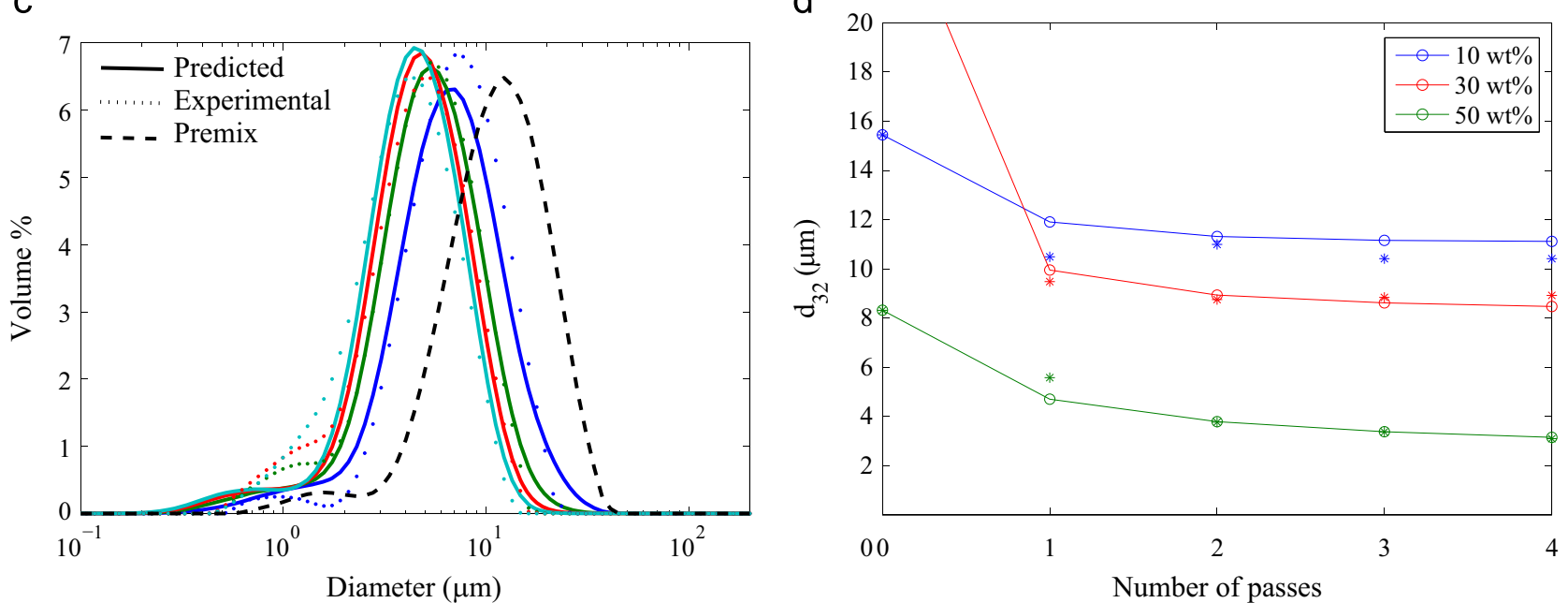

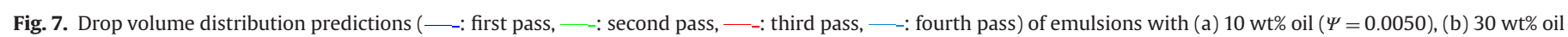

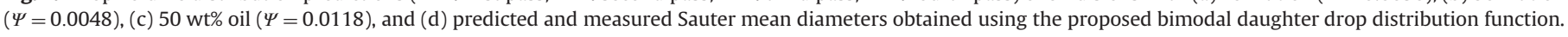


optimization (see below). Following volume discretization, 100 nonlinear ordinary differential equations were obtained in which time was the independent variable and the volume percent distribution at each node point were the dependent variables. The ODEs were solved by specifying the measured volume percent distribution of the coarse emulsion as the initial condition $n_{p}(v, 0)$ for the first pass through colloid mill. Each pass corresponded to the colloid mill residence time $t_{\text {res }}$, calculated as the ratio of volume between stator and rotor to the volumetric flow rate through the unit. The initial condition for each subsequent pass was the predicted volume percent distribution from the previous pass. The Matlab integration code ode15s was used to solve the ODE system.

Given a prespecified daughter drop distribution function, the constants $K_{1}-K_{4}$ in the coalescence and breakage functions were estimated from base case emulsification experiments (30 wt\% oil, 3 wt\% surfactant). The data used for parameter estimation consisted of the bulk emulsion properties $\left(\phi, \sigma, \eta_{e m}\right)$, operating conditions $\left(\dot{\gamma}, t_{\text {res }}\right)$, the measured premix volume distribution $\left(n_{p}(v, 0)\right)$, and measured volume distributions $n_{p}(v, t)$ for four passes through the colloid mill. The 100 ODEs obtained from volume discretization of the PBE model were temporally discretized using orthogonal collocation with 12 finite elements and 2 internal collocation points per element to produce a large set of nonlinear algebraic equations. Each pass corresponded to 3 finite elements. This set of algebraic equations was posed as a set of equality constraints in the nonlinear optimization problem. We found that additional spatial node points, finite elements, and/or collocation points did not affect the parameter estimates but increased the computational effort significantly. The least-square objective function $\Psi$ used for parameter estimation was

$\Psi=\frac{1}{N} \sum_{i=1}^{N} \frac{\sum_{j=1}^{n}\left[\hat{n}_{p}\left(v_{j}, i\right)-n_{p}\left(v_{j}, i\right)\right]^{2}}{\sum_{j=1}^{n}\left[n_{p}\left(v_{j}, i\right)\right]^{2}}$

${ }^{1}$ where $n_{p}\left(v_{j}, i\right)$ is the measured value of the drop volume distribution at drop volume $v_{j}$ and emulsification pass $\hat{i} \hat{n_{p}}\left(v_{j}, i\right)$ is the corresponding predicted value from the discretized PBE model; $n$ is the total number of spatial node points; and $N=4$ is the number of passes. The objective function was minimized subject to equality constraints representing the discretized PBE as well as continuity conditions across the finite elements. The optimization problem was formulated in AMPL (Fourer et al., 2003) and solved with the nonlinear program solver CONOPT (Drud, 1994). Furthermore, values of the objective function $\Psi$ were used to judge the quality of model predictions for different experiments.

\section{Results and discussion}

\subsection{Prediction of emulsion viscosity}

The adjustable parameters in the viscosity model (Eq. (14)) were estimated from the emulsion viscosity data shown in Fig. 3 and from $d_{32}$ values computed from measured drop size distributions. Data were collected over a range of oil fractions (10-70 wt\%) and shear rates (1-1000 1/s) determined by the operating limits of our rheometer. As the oil fraction was increased, the emulsion viscosity was observed to increase several orders of magnitude. Model predictions extrapolated to low and high shear rates are also shown in Fig. 3. Although not highly accurate, the model predictions captured the large changes in emulsion viscosity observed experimentally as the oil fraction was varied. The

\footnotetext{
${ }^{1}$ As $n_{p}\left(v_{j}, i\right)$ has some values equal to zero, least square errors were normalized by sum of $n_{p}\left(v_{j}, i\right)^{2}$ to avoid the denominator to go to zero.
}

emulsion viscosity $\eta_{e m}$ used in the PBE model was computed from the viscosity model as the plateau value at high shear rates.

\subsection{Evaluation of daughter drop distribution functions}

The adjustable parameters $K_{1}-K_{4}$ in the breakage and coalescence frequency functions were estimated from experimental data collected at the base case conditions (Table 1) to determine the most appropriate daughter drop distribution function. First parameter estimation was performed for each of the distribution functions shown in Table 3. The bell-shaped and U-shaped daughter drop distributions failed to capture the small peak at small drop sizes observed experimentally (Fig. 4(a), (b)). The U-shaped function also produced poor predictions at larger drop sizes, suggesting that most breakage events do not produce a single small drop and a single large drop. We also performed parameter optimization using the beta daughter drop distribution function with $p=20$ daughter drops (Fig. 4(c)) and $p=200$ daughter drops (Fig. 4(d)). Although the predicted drop size distributions matched well with data in the large drop size range, the models again failed to capture a second peak at small drop sizes. When predicted drop size distributions were converted to number distributions and compared to data, all fours daughter distributions were observed to produce large predictions errors (Fig. 5).

Next the proposed bimodal daughter distribution (Eq. (10)), which captures the breakage of drops into a relatively small number of larger drops and many small satellite drops, was used for parameter estimation. Based on preliminary simulation results (not shown), the parameters $M_{2}-M_{3}$ in the bimodal distribution that produced the best fit of the base case drop volume distribution data were determined as $M_{2}=38.3$ and $M_{3}=5.832 \times 10^{3}$. With these parameter values fixed, the adjustable parameters $K_{1}-K_{4}$ in the breakage and coalescence frequency functions were estimated as before. The bimodal distribution function produced substantially improved predictions of the volume and number drop size distributions as well as very accurate predictions of the Sauter mean diameter $d_{32}$ (Fig. 6). This bimodal distribution function was used throughout the remainder of the study.

\subsection{Effect of oil volume fraction}

The oil fraction was expected to have a strong impact on the drop size distribution, with higher oil fractions producing more drop collisions and smaller drop sizes. To investigate this effect, emulsification experiments were performed using four different oil fractions (10, 30, 50, $70 \mathrm{wt} \%)$ while maintaining a constant oilto-surfactant ratio (10/1). The colloid mill operating variables were held constant at their base values (5000 RPM rotor speed, $16 \mathrm{~kg} / \mathrm{h}$ flow rate, $2 \mathrm{~mm}$ gap size). Because emulsions with $70 \mathrm{wt} \%$ oil became too viscous to process after several passes through the colloid mill, drop volume distributions were collected only for the first two passes. The Sauter mean diameter was observed to decrease with increasing oil fraction (Fig. 7(d)) due to increased viscous shear stress. As has been previously reported (Zhao, 2007), bi-model drop size distributions were produced because large viscosity ratios tend to cause drop stretching with filaments that generate many small satellite drops in addition to larger daughter drops. Larger viscosity ratios were expected to produce a larger number of daughter drops due to increased stretching. While in principle this behavior could have been captured by making the daughter drop distribution function a function of the viscosity ratio, this approach would be complex and lead to difficult optimization problems.

Instead, the adjustable parameters $K_{1}-K_{4}$ were estimated for each oil fraction separately such that the breakage frequency would increase with increasing viscosity ratio. The PBE models 
produced satisfactory predictions of measured drop size distributions at 10, 30, and $50 \mathrm{wt} \%$ oil (Fig. 7). Moreover, the models were able to properly balance drop breakage and coalescence such that the predicted drop size distributions did not substantially change

a

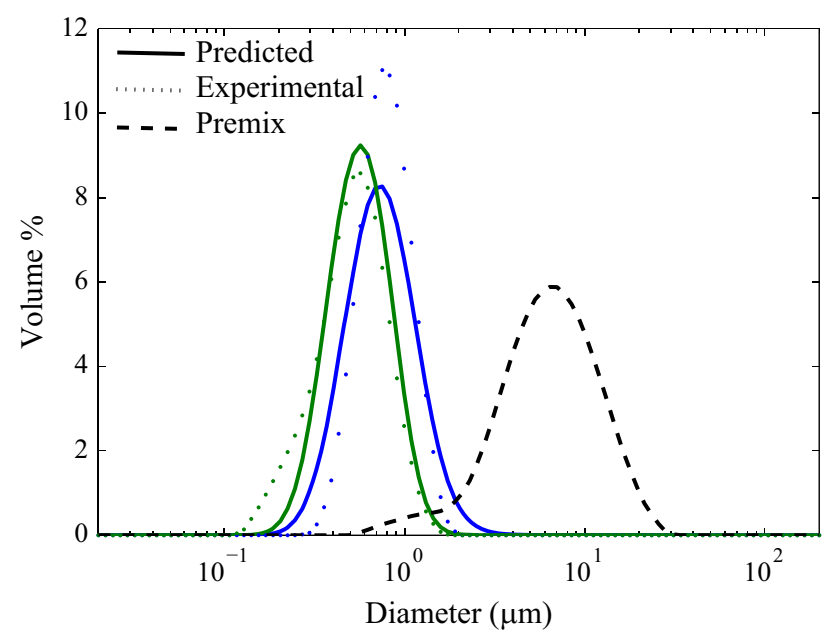

after the first pass as observed experimentally. For the $70 \mathrm{wt} \%$ oil emulsion, the viscosity ratio was less than one and drop breakage was expected to follow the proposed uni-modal daughter distribution function (Eq. (12)). Following estimation of the

b

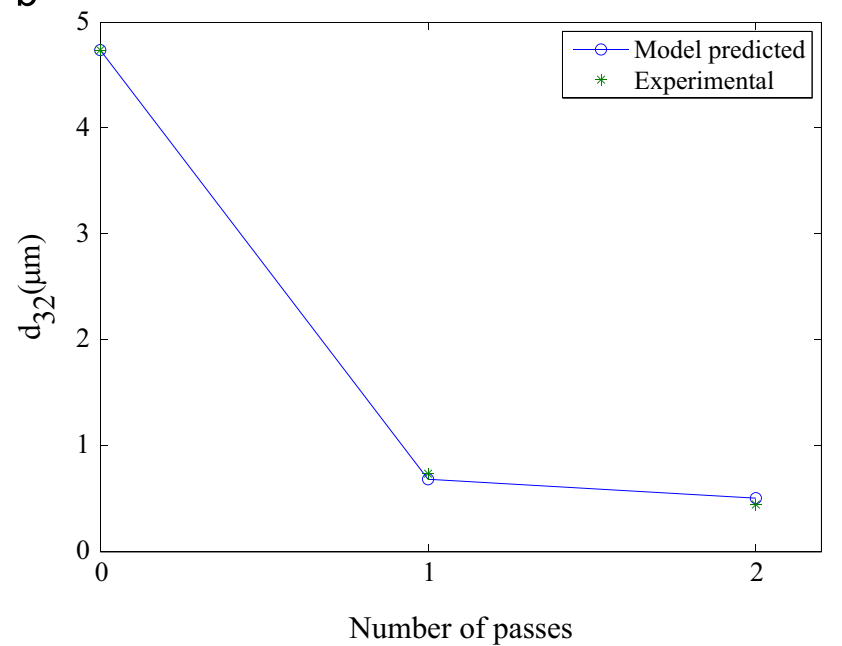

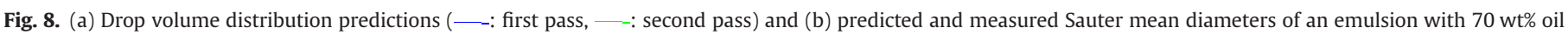
$(\Psi=0.059)$ obtained using the proposed uni-modal daughter drop distribution function.

a

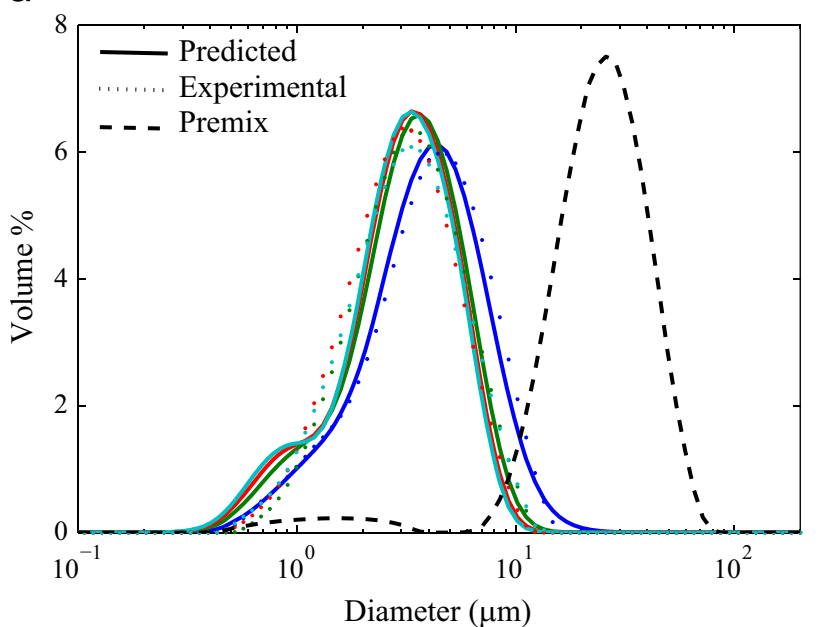

C

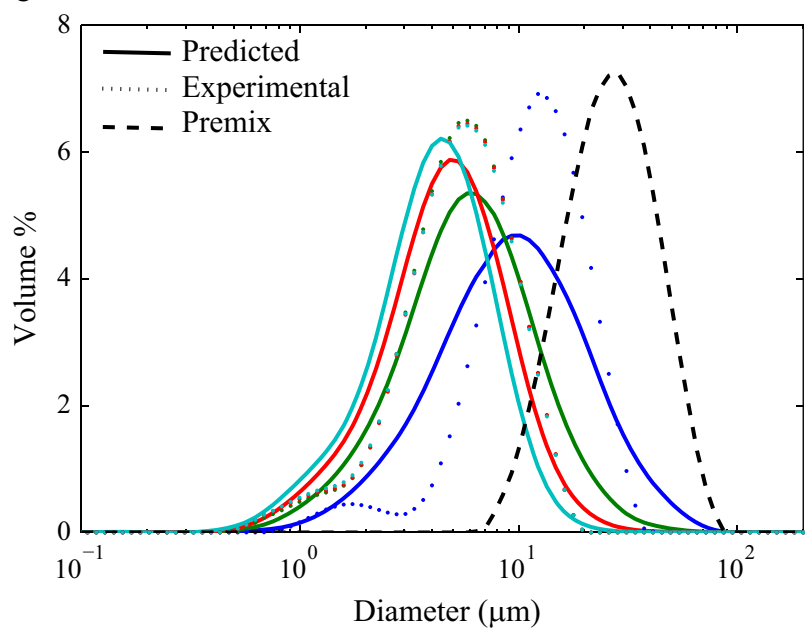

b

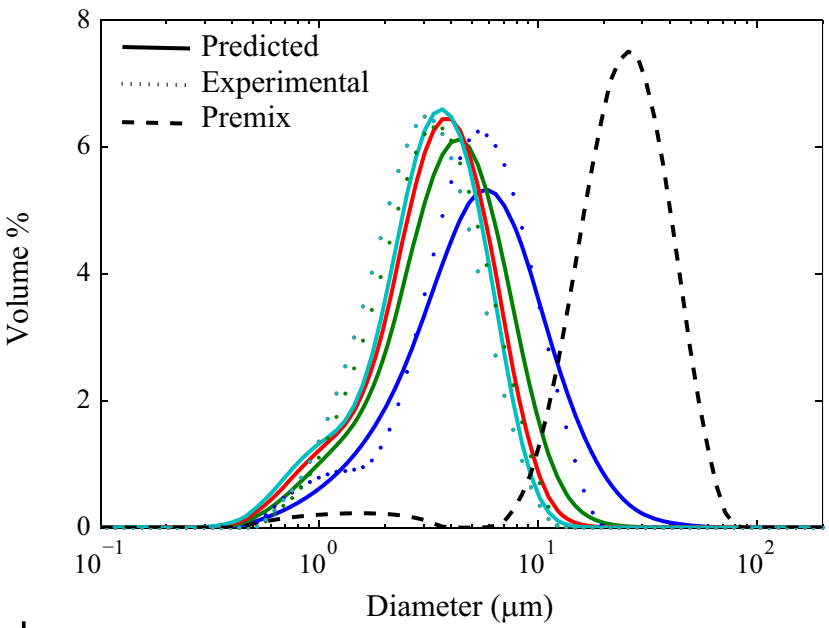

d

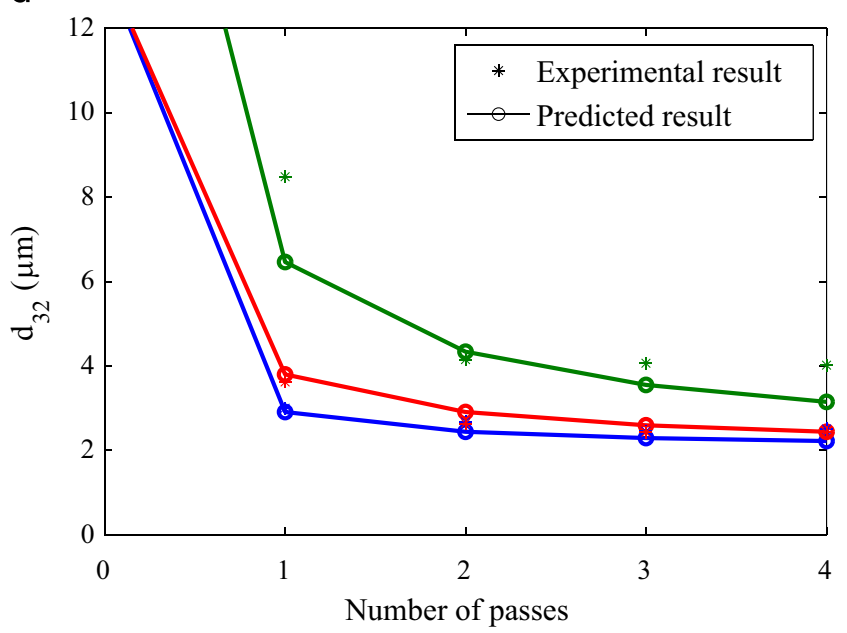

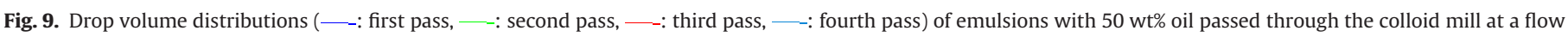

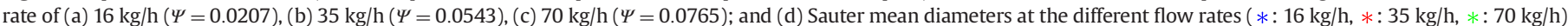
using model parameters estimated from data collected at $16 \mathrm{~kg} / \mathrm{h}$. 
adjustable model parameters $K_{1}-K_{4}$ with the uni-modal distribution function, the PBE model produced accurate predictions of the measured drop volume distributions (Fig. 8).

\subsection{Effect of flow rate}

The flow rate through the colloid mill affects the residence time, which in turn influences the degree of drop breakage. Higher flow rates are preferred to increase process throughput, while lower flow rates produce smaller drops. To investigate these trade offs, emulsification experiments were performed at three different flow rates $(16,35,70 \mathrm{~kg} / \mathrm{h})$ at high rotor speed (10,000 RPM) using emulsions with $50 \mathrm{wt} \%$ oil. As expected, increasing flow rates resulted in the formation of relatively large drops (Fig. 9(d)). The flow rate effect was most dominant at the highest flow rate $(70 \mathrm{~kg} / \mathrm{h}$ ) where the residence time was not sufficiently large to allow complete drop breakage, while the drop sizes obtained at the smaller flow rates $(16,35 \mathrm{~kg} / \mathrm{h})$ were very similar. To examine the ability of the PBE model to predict this trend, the parameters $K_{1}-K_{4}$ in the drop breakage functions and the parameters $M_{2}$ and $M_{3}$ in the daughter drop distribution function were estimated from data collected at a flow rate of $16 \mathrm{~kg} / \mathrm{hr}$ and used without reestimation to predict the drop volume distributions at the two higher flow rates. Only the residence time, calculated as the ratio of the volume between the stator and rotor to the volumetric flow rate, was varied between the three cases. The model produced very good agreement with the measured distributions at $16 \mathrm{~kg} / \mathrm{h}$ (Fig. 9(a)) and $35 \mathrm{~kg} / \mathrm{h}$ (Fig. 9(b)). However, the model overpredicted the degree of drop breakage for the first and forth passes at $70 \mathrm{~kg} / \mathrm{h}$ (Fig. 9(c)). These results suggest that some further model refinements may be needed to more accurately predict the flow rate effect.

\subsection{Effect of rotor speed}

According to Eq. (6), the shear rate is directly proportional to the rotor speed. Consequently, the rotor speed was expected to have a strong impact on the drop size distribution with increased drop breakage resulting from increased rotor speeds. To investigate this effect, emulsification experiments were performed at two rotor speeds $(5000,10,000 \mathrm{RPM})$ over a range of oil fractions (10, 30, 50, $70 w t \%)$. For each oil fraction, the PBE model parameters $K_{1}-K_{4}, M_{2}$ and $M_{3}$ were estimated from data collected at 5000 RPM and used to predict drop volume distributions at 10,000 RPM. In the case of $70 \mathrm{wt} \%$ oil, the emulsion was too viscous to be processed at 10,000 RPM and data was collected from a single a

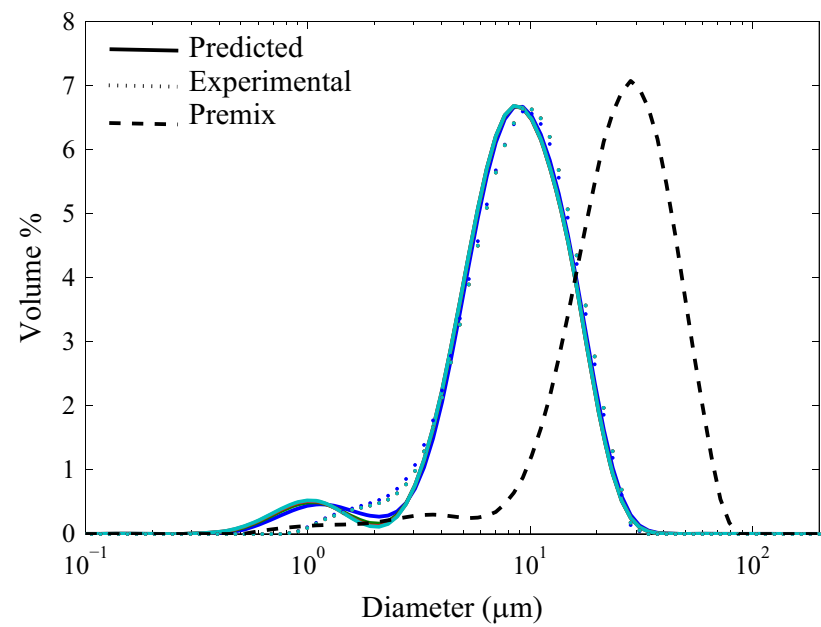

C

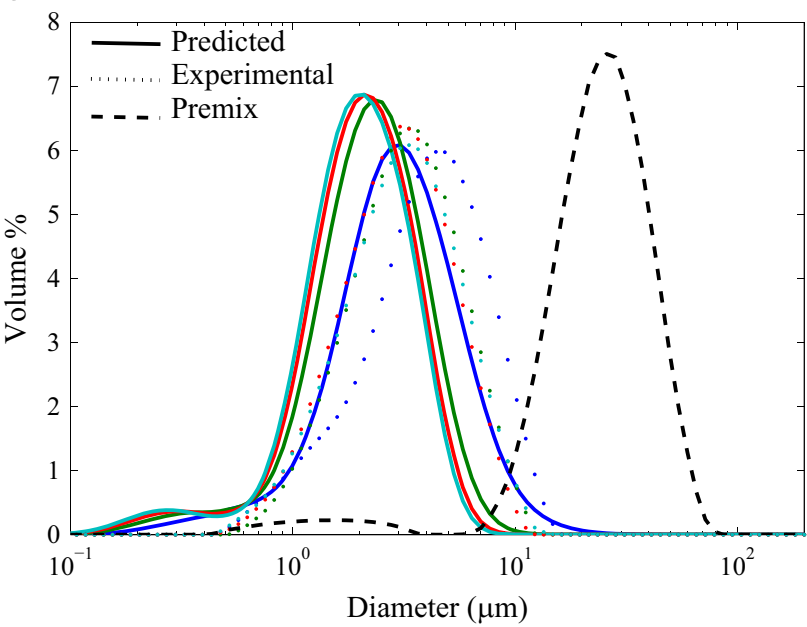

b

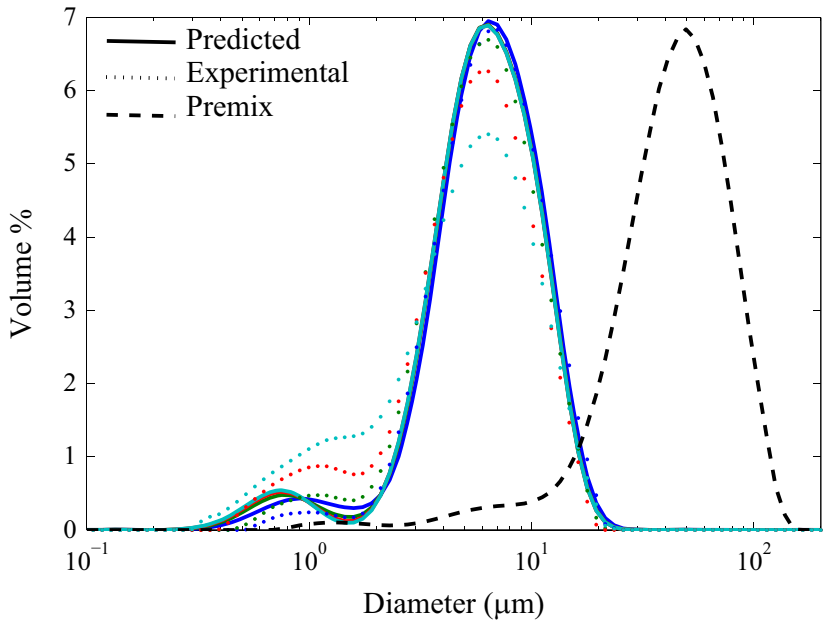

d

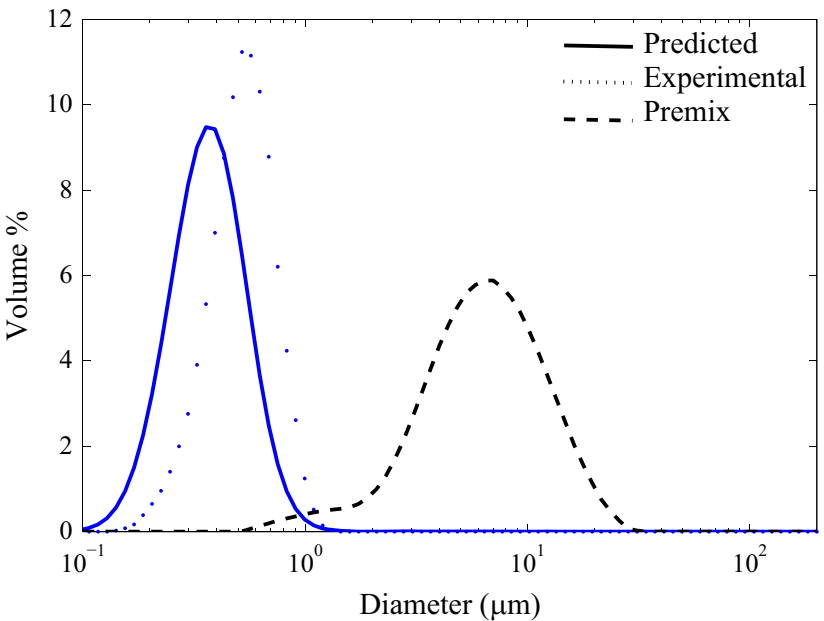

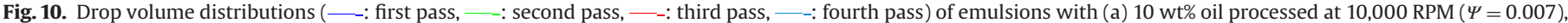
(b) $30 \mathrm{wt} \%$ oil processed at $10,000 \mathrm{RPM}(\Psi=0.0325)$, (c) $50 \mathrm{wt} \%$ oil processed at $10,000 \mathrm{RPM}(\Psi=0.325)$, and $(\mathrm{d}) 70 \mathrm{wt} \%$ oil processed at $8000 \mathrm{RPM}(\Psi=0.41)$, 
pass at 8000 RPM. While the model predictions were generally satisfactory at $10 \mathrm{wt} \%$ (Fig. 10(a)) and $30 \mathrm{wt} \%$ (Fig. 10(b)) oil, the model overpredicted drop breakage and/or under-predicted drop coalescence at $50 \mathrm{wt} \%$ (Fig. 10(c)) and $70 \mathrm{wt} \%$ oil (10(d)). One possibility for improving model predictions at high oil fractions is to allow the shear rate to depend nonlinearly on the rotor speed. This modification along with other attempts to improve model extensibility would require additional research.

\section{Conclusions}

We developed a population balance equation (PBE) model to predict drop size distributions in the colloid mill emulsification process. The model accounts for drop breakage due to capillary instability, drop coalescence due to shear driven drop collisions, and the effects of emulsion viscosity on the breakage and coalescence rates. We used the model to investigate drop breakage mechanisms and to examine predictive capability for changes in operating conditions. A published emulsion viscosity model was fit to viscosity data collected over a range of shear rates and oil fractions and extrapolated to very high shear rates for use within the PBE model. Our colloid mill produced bimodal drop size distributions that could not be predicted with functions commonly used for the daughter drop distribution, which determines the number and size of the drops that result from a breakage event. We proposed a new bimodal daughter distribution function that captured the formation of many small satellite drops and produced acceptable drop distribution predictions with respect to both volume percent and absolute number. While this bimodal distribution function proved satisfactory for emulsions with 10-50 wt $\%$ oil, a unimodal distribution function that captured more uniform drop breakage was used at $70 \mathrm{wt} \%$ oil to generate acceptable predictions. The oil fraction, flow rate and rotor speed were varied to examine model extensibility to new operating conditions with adjustable model parameters estimated from drop volume distribution measurements collected at a different operating condition. The model was reasonably extensible to different flow rates, while prediction accuracy for changes in rotor speed was less satisfactory. We believe our model represents the first attempt to develop a full PBE description of the colloid mill process and will provide a template for future research efforts aimed at predicting emulsion size distributions.

\section{References}

Almeida-Rivera, C., Bongers, P., 2010. Modelling and experimental validation of emulsification processes in continuous rotor-stator units. Comput. Chem. Eng. 34 (5), 592-597.

Almeida-Rivera, C., Bongers, P., 2012. Modelling and simulation of extensional-flow units in emulsion formation. Comput. Chem. Eng. 37, 33-39.

Alopaeus, V., Koskinen, J., Keskinen, K., 1999. Simulation of the population balances for liquid-liquid systems in a nonideal stirred tank. Part 1 - description and qualitative validation of the model. Chem. Eng. Sci. 54 (24), 5887-5899.

Alopaeus, V., Koskinen, J., Keskinen, K., Majander, J., 2002. Simulation of the population balances for liquid-liquid systems in a nonideal stirred tank. Part 2 - parameter fitting and the use of the multiblock model for dense dispersions. Chem. Eng. Sci. 57 (10), 1815-1825.

Alopaeus, V., Koskinen, J., Keskinen, K., 2003. Utilization of population balances in simulation of liquid-liquid systems in mixed tanks. Chem. Eng. Commun. 190 (11), 1468-1484.

Barnes, H.A., 1994. Rheology of emulsions: a review. Colloids Surf. A: Physicochem. Eng. Asp. 91, 89-95.

Boonen, E., Puyvelde, P.V., Moldenaers, P., 2010. Single droplet break-up in controlled mixed flows. ACS Appl. Mater. Interfaces 2 (7), 2140-2146.

Chesters, A., 1991. The modelling of coalescence processes in fluid liquid dispersions - a review of current understanding. Chem. Eng. Res. Des. 69, 259-270.

Coulaloglou, C., Tavlarides, L., 1977. Description of interaction processes in agitated liquid-liquid dispersions. Chem. Eng. Sci. 32 (11), 1289-1297.
Cristini, V., Guido, S., Alfani, A., Blawzdziewicz, J., Loewenberg, M., 2003. Drop breakup and fragment size distribution in shear flow. J. Rheol. 47 (5), 1283-1298.

De Bruijn, R., 1989. Deformation and Breakup of Drops in Simple Shear Flow (Ph.D. thesis), Eindhoven University of Technology, The Netherlands.

Derkach, S.R., 2009. Rheology of emulsions. Adv. Colloid Interface Sci. 151 (1), 1-23.

Drud, A.S., 1994. CONOPT - a large-scale GRG code. ORSA J. Comput. 6 (2), 207-216.

Drumm, C., Attarakih, M.M., Bart, H.-J., 2009. Coupling of CFD with DPBM for an RDC extractor. Chem. Eng. Sci. 64 (4), 721-732.

Fourer, R., Gay, D.M., Kernighan, B.W., 2003. AMPL: A Modeling Language for Mathematical Programming. Brooks/Cole Publishing Company, Pacific Grove, CA.

Grace, P., 1982. Dispersion phenomena in high-viscosity immiscible fluid systems and application of static mixers as dispersion devices in such systems. Chem. Eng. Commun. 14, 225-277.

Hakansson, A., Tragardh, C., Bergenstahl, B., 2009a. Dynamic simulation of emulsion formation in a high pressure homogenizer. Chem. Eng. Sci. 64 (12), 2915-2925.

Hakansson, A., Tragardh, C., Bergenstahl, B., 2009b. Studying the effects of adsorption, recoalescence and fragmentation in a high pressure homogenizer using a dynamic simulation model. Food Hydrocoll. 23 (4), 1177-1183.

Hill, P., Ng, K., 1996. Statistics of multiple particle breakage. AIChE J. 42 (6), $1600-1611$.

Jansen, K., Agterof, W., Mellema, J., 2001. Viscosity of surfactant stabilized emulsions. J. Rheol. 45, 1359-1371.

Janssen, J., Boon, A., Agterof, W., 1994. Droplet break-up in simple shear flow in the presence of emulsifiers. Colloids Surf. A: Physicochem. Eng. Asp. 91, 141-148.

King, A.G., Keswani, S.T., 1994. Colloid mills: theory and experiment. J. Am. Ceram. Soc. 77 (3), 769-777.

Klink, I., Phillips, R., Dungan, S., 2011. Effect of emulsion drop-size distribution upon coalescence in simple shear flow: a population balance study. J. Colloid Interface Sci. 353, 467-475.

Kostoglou, M., Karabelas, A., 2001. A contribution towards predicting the evolution of droplet size distribution in flowing dilute liquid/liquid dispersions. Chem. Eng. Sci. 56 (14), 4283-4292.

Kumar, S., Ramkrishna, D., 1996. On the solution of population balance equations by discretization 1. A fixed pivot technique. Chem. Eng. Sci. 51 (8), 1311-1332.

Liao, Y., Lucas, D., 2009. A literature review of theoretical models for drop and bubble breakup in turbulent dispersions. Chem. Eng. Sci. 64 (15), 3389-3406.

Li, Q.-S., Wen, P., Xu, L.-X., 2010. Transition to Taylor vortex flow between rotating conical cylinders. J. Hydrodyn. Ser. B 22 (2), 241-245.

Maindarkar, S., Raikar, N., Henson, M., 2012. Incorporating emulsion drop coalescence into population balance equation models of high pressure homogenization. Colloids Surf. A-Physicochem. Eng. Asp. 396, 63-73.

Maindarkar, S.N., Bongers, P., Henson, M.A., 2012. Predicting the effects of surfactant coverage on drop size distributions of homogenized emulsions. Chem. Eng. Sci. 89, 102-114.

McClements, D.J., 2005. Food Emulsions: Principles, Practice, and Techniques. CRC Press, Boca Raton, FL.

Pal, R., 2001. Novel viscosity equations for emulsions of two immiscible liquids. J. Rheol. 45, 509.

Pandolfe, W., 1996. Emulsion and dispersion generation - a look at homogenizers, colloid mills and mixer/emulsifiers. Chem. Process. 59, 59-65.

Raikar, N., Bhatia, S., Malone, M., Almeida-Rivera, C., Bongers, P., McClements, D., Henson, M., 2010. Prediction of emulsion drop size distributions with population balance equation models of multiple drop breakage. Colloids Surf. A: Physicochem. Eng. Asp. 361 (1), 96-108.

Raikar, N., Bhatia, S., Malone, M., Henson, M., 2009. Experimental studies and population balance equation models for breakage prediction of emulsion drop size distributions. Chem. Eng. Sci. 64 (10), 2433-2447.

Ramkrishna, D., 2000. Population Balances: Theory and Applications to Particulate Processes in Engineering. Academic Press, New York, NY.

Renardy, Y., Cristini, V., Li, J., 2002. Drop fragment distributions under shear with inertia. Int. J. Multiph. Flow 28 (7), 1125-1147.

Ruiz, M., Padilla, R., 2004. Analysis of breakage functions for liquid-liquid dispersions. Hydrometallurgy 72 (3-4), 245-258.

Ruiz, M., Lermanda, P., Padilla, R., 2002. Drop size distribution in a batch mixer under breakage conditions. Hydrometallurgy 63 (1), 65-74.

Simon, M., Schmidt, S., Bart, H., 2003. The droplet population balance model estimation of breakage and coalescence. Chem. Eng. Technol. 26 (7), 745-750.

Sovova, H., 1981. Breakage and coalescence of drops in a batch stirred vessel - II comparison of model and experiments. Chem. Eng. Sci. 36 (9), 1567-1573.

Sovova, H., Prochazka, J., 1981. Breakage and coalescence of drops in a batch stirred vessel - I comparison of continuous and discrete models. Chem. Eng. Sci. 36 (1), $163-171$.

Walstra, P., 1993. Principles of emulsion formation. Chem. Eng. Sci. 48 (2), 333-349.

Wieringa, J., Van Dieren, F., Janssen, J., Agterof, W., 1996. Droplet breakup mechanisms during emulsification in colloid mills at high dispersed phase volume fraction. Chem. Eng. Res. Des. 74 (5), 554-562.

Zhang, H., Zhang, K., Fan, S., 2009. CFD simulation coupled with population balance equations for aerated stirred bioreactors. Eng. Life Sci. 9 (6), 421-430.

Zhao, X., 2007. Drop breakup in dilute Newtonian emulsions in simple shear flow: New drop breakup mechanisms. J. Rheol. 51 (3), 367-392. 